\title{
Assessment and statistical analysis of global radiation by decomposing it to its direct and diffuse components
}

\author{
S. PASHIARDIS ${ }^{1 *}$, S.A. KALOGIROU ${ }^{1,2}$ \\ ${ }^{1}$ Department of Mechanical Engineering and Materials Science and Engineering \\ Cyprus University of Technology, P. O. Box 50329, 3603, Limassol, Cyprus
}

${ }^{2}$ Founding Member of the Cyprus Academy of Sciences, Letters, and Arts

Tel: +357-2500-2621, Fax: +357-2500-2637, Email: soteris.kalogirou@cut.ac.cy

\begin{abstract}
In this work, hourly measurements of global solar irradiances obtained from a pyranometer and direct normal irradiances obtained from sunshine duration sensor are assessed through an extensive quality control procedure and statistical analysis on the measured and derived solar parameters for a semimountainous location using data from the last five years (2016-2020). This information and the method suggested concerning the solar energy capture systems and energy efficiency is useful for engineers who can therefore take knowledge of the local radiation levels. Furthermore, the direct horizontal irradiance can be easily calculated and the diffuse component can be estimated from the difference of global and direct horizontal irradiances. Monthly mean hourly values of the radiation components are also estimated and shown through isolines diagrams. Representative values of global direct and diffuse irradiances for different times of the year and different hour of the day can be easily read from these diagrams. Simultaneously, a similar analysis is carried out over various solar indices estimated on both hourly and daily basis. The derived solar indices are the clearness index for global, direct and diffuse radiation as well as the diffuse and direct fractions from global radiation. The interrelationships between the said indices are also examined. Additionally, the BRL (Boland-Ridley-Lauret) diffuse fraction model which is a multiple predictor logistic model was tested and can be used to estimate the diffuse and later the direct radiation component. The model is a function of clearness index $\left(\mathrm{k}_{\mathrm{t}}\right)$, the apparent solar time (AST), the solar altitude $\left(\alpha_{\mathrm{s}}\right)$, the daily clearness index $\left(\mathrm{K}_{\mathrm{T}}\right)$ and persistence parameter $\psi$ which is an average of both a lag and lead of the clearness index. The outcome of the model shows that it can be used to estimate successfully the diffuse radiation.
\end{abstract}




\section{التقييم والتحليل الإحصائي للإشعاع الكلى بتحليله إلى مركباته المباشرة والمنتشرة}

س. باشيارديس ${ }^{1}$ و س. ا. كالوجيرو 2,1"

1 قسم الهندست الميكانيكيت وعلوم وهندست المواد ـ جامعتّ قبرص للتكنولوجيا ، ص.ب 3603 ، 50329،

ليماسول ، قبرص

2 عضو مؤسس في أكاديميتش قبرص للعلوم والآداب والفنون ليمون

ملخص: يتتاول العمل الحالي تقييم القياسات الساعيت لإِشعاعات الشمسيت الكليت التي تم الحصول عليها من

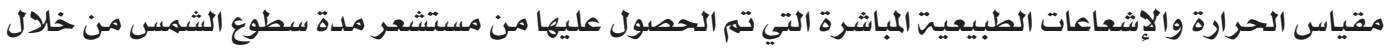

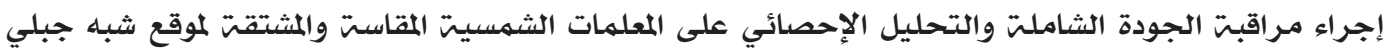

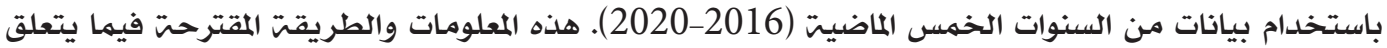

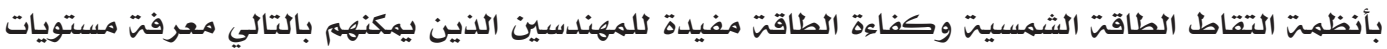

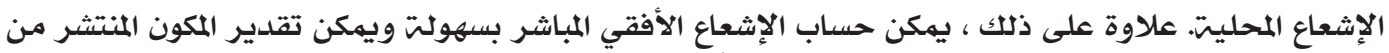

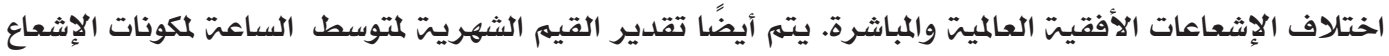

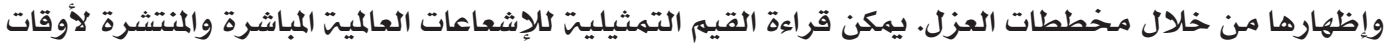

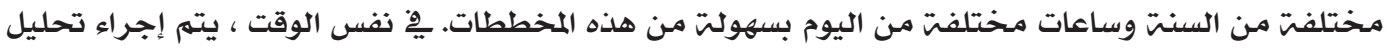

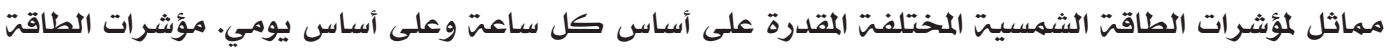

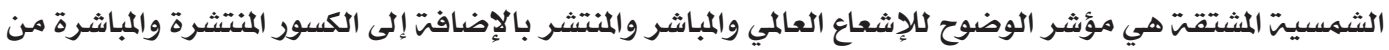

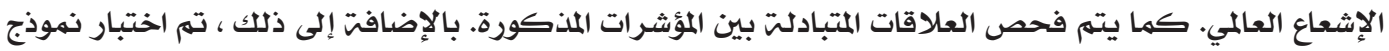

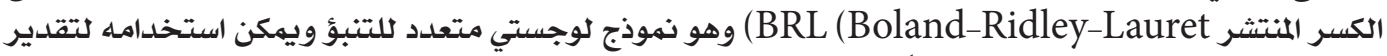

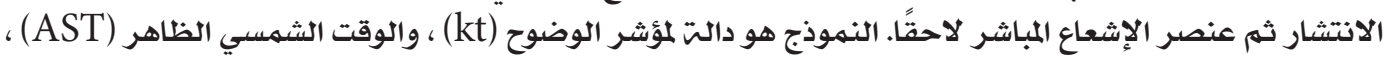

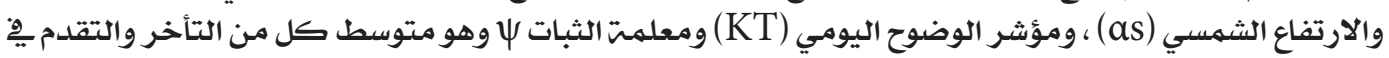

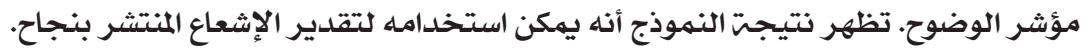

Keywords: quality control of solar radiation, solar radiation indices, statistical analysis, isoline diagrams, modeling diffuse radiation.

\section{INTRODUCTION}

Knowledge of the local solar radiation profile is essential to properly design solar energy systems. Solar energy is used in many applications that seek to optimize the capture of solar energy, so that, it is possible to reach energy savings and carry out sustainable energy consumption. Furthermore, solar radiation data are important for applications in meteorology, agriculture, crop modeling as well as in the health sector. Most of the solar radiation data registered by weather stations are global irradiance data measured on a horizontal surface. Additionally, solar radiation fractions, such as the direct and diffuse fractions, are required for several applications. As an example, the direct component is a basic input to predict the performance and to design concentrating solar plants. As global solar irradiance is more commonly measured at radiometric stations than their components, direct and diffuse components must be obtained through models. Different models can be found in literature to estimate these components.

Global irradiance estimation and the prediction of its components, i.e. direct, diffuse and reflected radiation are widely discussed in literature. Considerable work has been done since the pioneer contribution 
by Liu and Jordan (1960). Since then, several models and comparative analyses are presented and discussed. An extensive review of the measurements and modeling of all shortwave radiation components is given by Badescu (2008). In general, different models exist to predict solar irradiance. Two categories of solar radiation models can be distinguished: a) models that are based on meteorological data, such as cloudiness, sunshine duration, turbidity of the atmosphere and b) models that use global horizontal irradiance (Gueymard, 2010). Examples from the first category are the Bird model (1981), METSTAT (1998), the REST2 (2008) and Ineichen model (2008). Details about the computation procedure of the said models are given by Myers (2013). Gueymard found that these models are consistently capable in predicting the solar irradiances. In the second group we can classify the models which use the decomposition method by which global irradiance is splitted into its direct and diffuse components and are basically based on the clearness index (Gueymard, 2010). In this category we can classify the Orgill and Hollands (1977), Erbs et al. (1982) Skartveit et al. (1998) and Boland et al. (2008) to mention some of them. The separation models are still highly popular. They are often described in the literature as site-dependent, since they are essentially empirical in nature. Bolland model however, was found to perform satisfactorily at different sites.

The first objective of this work is to assess the measurements obtained by pyranometer and sunshine duration sensors through an extensive quality control procedure and perform statistical analysis on the measured and derived parameters. High accuracy measurements of direct normal irradiances can be obtained by pyrheliometers, but these are costly and therefore are too scarce for proper temporal or spatial coverage. For this purpose the sunshine duration sensor is used to measure the direct normal irradiance at an acceptable accuracy. Then, the direct horizontal irradiance can be easily calculated and the diffuse component can be estimated from the difference of global and direct horizontal irradiances. The second objective of this work is the implementation of BRL (Boland-Ridley-Lauret) diffuse fraction model which is a multiple predictor logistic model developed by Ridley et al. (2010) and can be used to estimate the diffuse and later the direct radiation component. The model is a function of clearness index $\left(\mathrm{k}_{\mathrm{t}}\right)$, the apparent solar time (AST), the solar altitude $\left(\alpha_{\mathrm{s}}\right)$, the daily clearness index $\left(\mathrm{K}_{\mathrm{T}}\right)$ and persistence parameter $\psi$ which is an average of both a lag and lead of the clearness index.

The paper is organized as follows: Section 2 describes the materials and methods which are used to estimate direct horizontal and diffuse irradiances including the quality control procedure which was followed for both hourly and daily values. Section 3 presents a detailed statistical analysis of all radiation components and the derived radiation indices for both hourly and daily values. A subsection is devoted for the implementation of BRL model. Finally, section 4 concludes this paper and provides suggestions for future research.

\section{MATERIALS AND METHODS}

Hourly data of global horizontal irradiance $(G)$ were obtained from the automatic weather station of Farmakas, a semi-mountainous location in Cyprus at the height of $833 \mathrm{~m}$, covering the period 20162020. A CM-11 Kipp \& Zonen pyranometer was used for the measurements and the experimental error is approximately $2-3 \%$. Its sensitivity is $8.21 \mu \mathrm{V} / \mathrm{W} / \mathrm{m}^{2}$. For the sunshine duration data, a Kipp \& Zonen CSD3 sunshine duration sensor is used. The sensor is facing south with a slope $(\beta)$ of $35^{\circ}$ (local latitude) from the horizontal plane. Sunshine duration is defined by WMO as the time during which the direct solar radiation exceeds the level of $120 \mathrm{~W} / \mathrm{m}^{2}$. The sensor, at the same time, estimates internally the direct normal irradiance $\left(B_{n}\right)$ in $\mathrm{W} / \mathrm{m}^{2}$. The estimated value is less accurate than the value obtained by the pyrhiliometer which is installed at a solar tracker system (Kipp \& Zonen, personal communication). The photosynthetic active radiation is measured by the PAR-LITE Quantum Sensor of Kipp \& Zonen company and its sensitivity is 5.14 $\mu \mathrm{V} / \mu \mathrm{mol} / \mathrm{s} \mathrm{m}^{2}$ with an experimental error of about $5 \%$. This measurement represents the number of photons between 400 and $700 \mathrm{~nm}$ incidents per square meter per second. The conversion factor of $4.57 \mu \mathrm{mol} / \mathrm{J}$ (or $\mu \mathrm{mol} / \mathrm{s} / \mathrm{W}$ ) proposed by McCree (1972) is used to convert PPFD into its energy alternative (i.e., PARE). All the sensors are factory calibrated. Additionally, the station is equipped with air temperature and relative humidity sensors which are installed at the screen level of $1.2 \mathrm{~m}$ above the surface. The station's coordinates 
are presented in Table 1 and the location of the station is shown in Figure 1.

Table (1). Station's coordinates and mean annual air temperature $\left(T_{a}\right)$, Relative humidity $(\mathrm{RH})$ and annual number of sunshine duration $\left(\mathrm{S}_{\mathrm{d}}\right)$.

\begin{tabular}{|c|c|c|c|c|c|c|c|}
\hline Station & $\begin{array}{c}\text { Long. (E) } \\
(\text { deg.) }\end{array}$ & $\begin{array}{c}\text { Lat. (N) } \\
\text { (deg.) }\end{array}$ & Elev. (m) & Distance ${ }^{1}$ & $\mathrm{Ta}\left({ }^{0} \mathrm{C}\right)$ & $\mathrm{RH}(\%)$ & $\mathrm{Sd}(\mathrm{hrs})$ \\
\hline Farmakas & 33.134 & 34.921 & 833 & 23 & 16.9 & 56 & 2555 \\
\hline
\end{tabular}

Note: $1=$ Shortest distance from coast in $\mathrm{Km}$.

The average air temperature in summer is about $27^{\circ} \mathrm{C}$ while during the winter is about $9^{\circ} \mathrm{C}$. The maximum air temperature exceeds the value of $40{ }^{\circ} \mathrm{C}$ on some days in the summer, while the lowest air temperature reaches $-5^{\circ} \mathrm{C}$ in winter. The average annual rainfall is about $700 \mathrm{~mm}$ and occurs between October and May. The summer season is dry with clear sky conditions. Periodically, the island is under the effect of the Saharan Air Layer which is characterized by high content of mineral dust. Dust conditions are more frequent in spring and autumn, although they are observed in some cases in winter and summer. The prevailing wind direction is north-easterly during the day and south to south-easterly during the night. The average annual daily global radiation is $17.5 \mathrm{MJ} / \mathrm{m}^{2}$ and the cumulative annual irradiation is about $6400 \mathrm{MJ} / \mathrm{m}^{2}$. The annual number of sunshine duration is about 2555 hours and about 148 days are considered as clear days. On the other hand, cloudy conditions are recorded for about 44 days, and the respective number of partially cloudy days is 173 days.

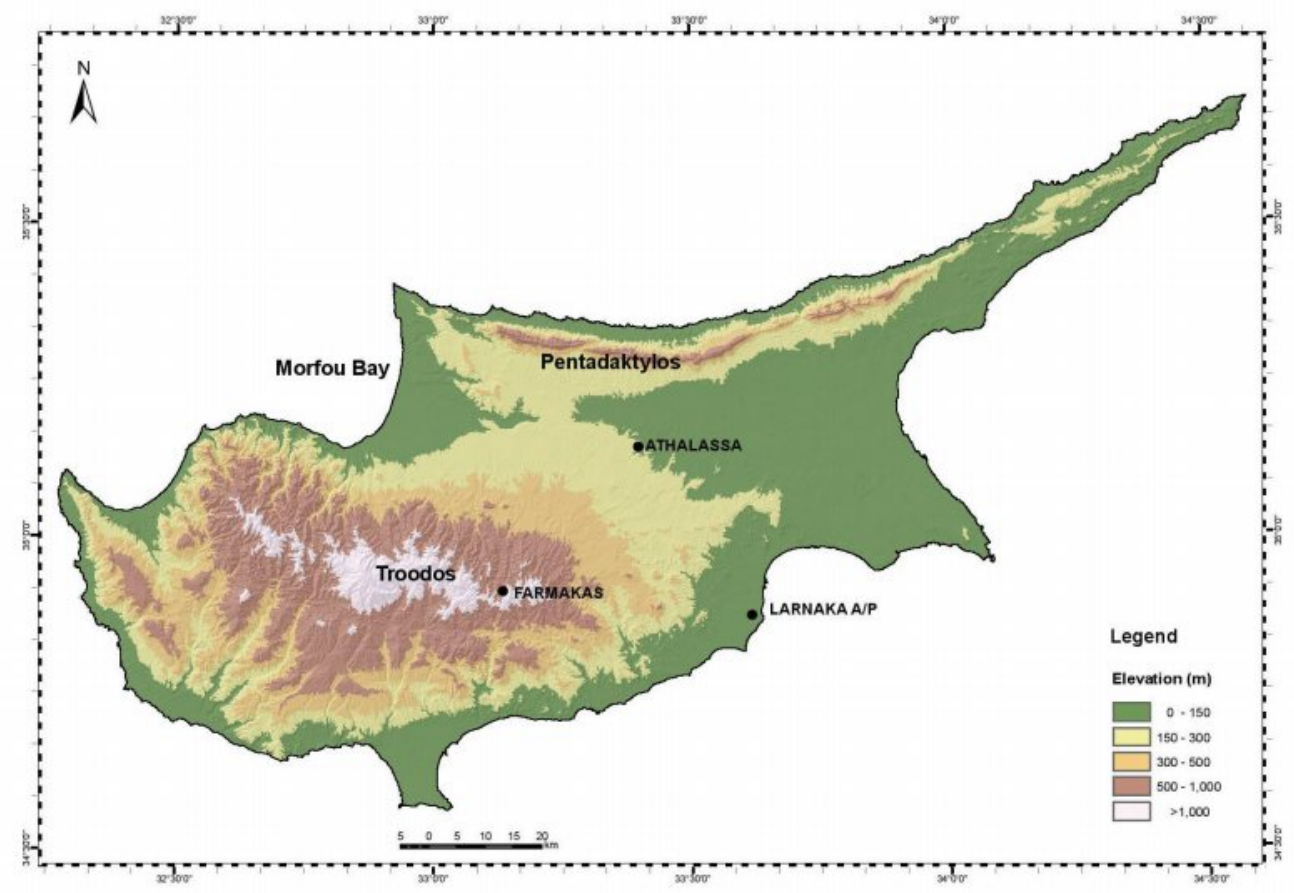

Figure (1). Map of Cyprus showing the location of Farmakas and actinometric stations of Athalassa and Larnaca.

\subsection{Estimation of direct irradiance on a horizontal surface}

According to Myers (2013), the horizontal beam irradiance (B) can be calculated from the normal beam irradiance $\left(\mathrm{B}_{\mathrm{n}}\right)$ from the following equation: 
$\mathrm{B}=\mathrm{B}_{\mathrm{n}} \cos \left(\theta_{\mathrm{z}}\right)$

where $\theta_{z}$ is the solar zenith angle (SZA) which is given by:

$\cos \theta_{z}=\cos \phi \cos \delta \cos \omega+\sin \phi \sin \delta$

where, $\varphi$ is the latitude of the location, $\delta$ is the solar declination angle (deg) and $\omega$ is the hour angle (deg). The solar declination and hour angles are estimated by the following equations:

$\delta=23.45 \sin \left(360 \times\left(284+d_{n}\right) / 365\right)$

$\omega=(\mathrm{AST}-12) / 15$

where $d_{n}$ is the day of the year (1..365) and AST is the apparent solar time for the given day in hours. The local time (t) is converted to solar time (AST) using the following equation:

$\mathrm{AST}=\mathrm{t}-4\left(\lambda_{\mathrm{st}}-\lambda\right)+\mathrm{E}_{\mathrm{t}}-\mathrm{c}$

where $\mathrm{c}$ is the correction for summer time ( $\mathrm{c}=1$ for summer and $\mathrm{c}=0$ for winter), $\lambda_{s t}$ is the reference longitude of the time zone which is positive to the east of Greenwich and for Cyprus is $30^{\circ}, \lambda$ is the longitude of the location and $\mathrm{E}_{\mathrm{t}}$ is the equation of time in minutes and can be estimated from the following equations:

$\mathrm{E}_{\mathrm{t}}=9.87 \sin 2 \mathrm{~A}-7.53 \cos \mathrm{A}-1.5 \sin \mathrm{A}$

where

$\mathrm{A}=360\left(\mathrm{~d}_{\mathrm{n}}-81\right) / 365$

Then, the hourly diffuse irradiance (D) is the difference between the global and the horizontal beam irradiance:

$\mathrm{D}=\mathrm{G}-\mathrm{B}$

The irradiance falling on a plane at normal incidence at the top of the atmosphere $\left(\mathrm{G}_{0 \mathrm{n}}\right)$ can be estimated from the following equation:

$$
\mathrm{G}_{0 \mathrm{n}}=\mathrm{G}_{\mathrm{sc}}\left[1+0.033 \cos \left(360 \times \mathrm{d}_{\mathrm{n}} / 365\right)\right] \quad\left(\mathrm{W} / \mathrm{m}^{2}\right)
$$

Where $\mathrm{G}_{\mathrm{sc}}$ is the solar constant $\left(1367 \mathrm{~W} / \mathrm{m}^{2}\right)$. Then, the irradiance on a horizontal plane at the top of the atmosphere can be estimated by the following equation:

$$
\mathrm{G}_{0}=\mathrm{G}_{0 \mathrm{n}} \cos \theta_{\mathrm{z}}=\mathrm{G}_{0 \mathrm{n}}(\cos \phi \cos \delta \cos \omega+\sin \phi \sin \delta) \quad\left(\mathrm{W} / \mathrm{m}^{2}\right)
$$

Then, the daily total global irradiation which is obtained by a horizontal plane at the top of the atmosphere $\left(\mathrm{G}_{0 \mathrm{~d}}\right)$ is obtained by integrating Eq. 10 from sunrise to sunset and is given by the following equation:

$$
\mathrm{G}_{0 \mathrm{~d}}=(24 \times 360 / \pi) \mathrm{G}_{0 \mathrm{n}}\left[\left(\cos \phi \cos \delta \sin \omega_{\mathrm{s}}+\left(\pi \omega_{\mathrm{s}} / 180\right) \sin \phi \sin \delta\right)\right] \quad\left(\mathrm{W} / \mathrm{m}^{2}\right)
$$

where $\omega_{s}$ is the sunset hour angle and is given by:

$\omega_{\mathrm{s}}=\cos ^{-1}(-\tan \phi \tan \delta)$

The daily sums of global and horizontal beam radiation are obtained from the hourly values. Therefore, the daily diffuse irradiation $\left(\mathrm{D}_{\mathrm{d}}\right)$ on a horizontal surface can be estimated by: 
$D_{d}=G_{d}-B_{d}$

Furthermore, the astronomical day length $\left(\mathrm{S}_{0 \mathrm{~d}}\right)$ which is the computed time during which the center of the solar disk is above an altitude of zero degrees (without allowance for atmospheric refraction) is given by:

$$
\mathrm{S}_{0 \mathrm{~d}}=(1 / 1.75) \cos ^{-1}(-\tan \phi \tan \delta) \quad(\mathrm{hrs})
$$

\subsection{Quality Control process}

\subsubsection{Quality control of hourly values}

To check for any major problems with the data before testing every single variable, fingerprint plots are used to demonstrate the variation of the radiation components. In these plots the x-axis represents a day in the year and the y-axis represents an hour of the day, with a color scale from blue to red showing the various levels of the presented variables. The graphs (not shown here) do not show any major problem with the measurements.

The quality control procedures for the solar irradiances are based on checking whether the measurements are within certain limits, such as physically possible limits (PPL), extremely rare limits (ERL), and configurable limits as proposed by BSRN group (Long and Shi, 2008). The PPL process checks extremely large errors in radiation data, while the ERL process identifies cases which exceed the rare limits over very short time periods. The lower bound of the limits is naturally zero, although BSRN suggests $-4 \mathrm{~W} / \mathrm{m}^{2}$ for PPL and $-2 \mathrm{~W} / \mathrm{m}^{2}$ for ERL lower limits of the radiation components. The upper bound of these limits is shown in Table 2a. Furthermore, the BSRN group has proposed configurable limits based on several years of measurements in various sites in the United States. Based on the radiation measurements of the Great Plains of the continental USA, the formulas for these tests are given in Table $2 \mathrm{~b}$. The limits labeled ' 1 st level' are the smallest testing limits, while those labeled ' 2 nd level' are the second set of limits. Data above these limits are excluded from the data set.

Table (2a). The upper bounds for the 'physically possible' (PPL) and 'extremely rare' (ERL) limits as proposed by BSRN group, which are used for checking the radiation parameters.

\begin{tabular}{|c|c|c|}
\hline Parameter & \multicolumn{2}{|c|}{ Upper bound (W/m²) } \\
\hline & PPL & ERL \\
\hline Global Irradiance $(G)$ & $1.5 \times \mathrm{G}_{0 \mathrm{n}}\left(\cos \theta_{\mathrm{z}}\right)^{1.2}+100$ & $1.2 \times \mathrm{G}_{0 \mathrm{n}}\left(\cos \theta_{\mathrm{z}}\right)^{1.2}+50$ \\
\hline Direct Normal Irradiance $\left(B_{n}\right)$ & $\mathrm{G}_{0 \mathrm{n}}$ & $0.95 \times \mathrm{G}_{0 \mathrm{n}}\left(\cos \theta_{z}\right)^{0.2}+10$ \\
\hline Direct Horizontal. $\operatorname{Irr}\left(\mathrm{B}_{\mathrm{h}}\right)$ & $\mathrm{G}_{0 \mathrm{n}}\left(\cos \theta_{\mathrm{z}}\right)$ & $0.95 \times \mathrm{G}_{0 \mathrm{n}}\left(\cos \theta_{\mathrm{z}}\right)^{1.2}+10$ \\
\hline Diffuse Irradiance (D) & $0.95 \times \mathrm{G}_{0 \mathrm{n}}\left(\cos \theta_{\mathrm{z}}\right)^{1.2}+50$ & $0.75 \times \mathrm{G}_{0 \mathrm{n}}\left(\cos \theta_{\mathrm{z}}\right)^{1.2}+30$ \\
\hline
\end{tabular}


Table (2b). The configurable upper limits (1st and 2nd levels') for checking the radiation parameters.

\begin{tabular}{|c|c|c|}
\hline Parameter & Configurable Limits $\left(\mathrm{W} / \mathrm{m}^{2}\right)$ & Level \\
\hline \multirow{2}{*}{ Global Horizontal Irradiance (G) } & $0.97 \times \mathrm{G}_{0 \mathrm{n}}\left(\cos \theta_{\mathrm{z}}\right)^{1.2}+55$ & $2^{\text {nd }}$ \\
\hline & $0.92 \times \mathrm{G}_{0 \mathrm{n}}\left(\cos \theta_{\mathrm{z}}\right)^{1.2}+50$ & $1^{\mathrm{st}}$ \\
\hline \multirow{2}{*}{ Direct Normal Irradiance $\left(B_{n}\right)$} & $0.86 \times \mathrm{G}_{0 \mathrm{n}}\left(\cos \theta_{\mathrm{z}}\right)^{0.2}+15$ & $2^{\text {nd }}$ \\
\hline & $0.82 \times \mathrm{G}_{0 \mathrm{n}}\left(\cos \theta_{\mathrm{z}}\right)^{0.2}+10$ & $1^{\text {st }}$ \\
\hline \multirow{2}{*}{ Direct Horizontal Irradiance (B) } & $0.86 \times \mathrm{G}_{0 \mathrm{n}}\left(\cos \theta_{z}\right)^{1.2}+15$ & $2^{\text {nd }}$ \\
\hline & $0.82 \times \mathrm{G}_{0 \mathrm{n}}\left(\cos \theta_{\mathrm{z}}\right)^{1.2}+10$ & $1^{\text {st }}$ \\
\hline \multirow{2}{*}{ Diffuse Horizontal Irradiance (D) } & $0.58 \times \mathrm{G}_{0 \mathrm{n}}\left(\cos \theta_{\mathrm{z}}\right)^{1.2}+35$ & $2^{\text {nd }}$ \\
\hline & $0.52 \times \mathrm{G}_{0 \mathrm{n}}\left(\cos \theta_{\mathrm{z}}\right)^{1.2}+30$ & $1^{\text {st }}$ \\
\hline
\end{tabular}

The following plots illustrate the various tests outlined in the preceding paragraphs based on 5 year measurements and estimations of shortwave irradiances. Figure 2 shows the highest limits of global, direct horizontal and diffuse irradiances. The analysis shows that all the data are within the proposed limits. Quite a few observations are outside the configurable limits of global irradiance. The clear sky beam horizontal irradiance is based on the Linke turbidity factor and is given by Scharmer and Greif,2000):

$$
\begin{aligned}
& \mathrm{B}_{\mathrm{c}}=1367 \times \varepsilon \exp \left(-0.8662 \mathrm{~T}_{\mathrm{LK}} \times \mathrm{m} \times \delta_{\mathrm{r}}(\mathrm{m})\right) \cos \theta_{z} \\
& \mathrm{~m}=\left(\mathrm{P} / \mathrm{P}_{0}\right) /\left(\sin \alpha_{\mathrm{s}}+0.50572\left(\alpha_{\mathrm{s}}+6.07995\right)^{-1.6364}\right) . .
\end{aligned}
$$

where $\varepsilon$ is the correction factor to mean solar distance, $\mathrm{T}_{\mathrm{LK}}$ is the Linke turbidity factor, $\mathrm{m}$ is the optical air mass corrected for the station height and $\delta_{\mathrm{r}}(\mathrm{m})$ is the Rayleigh optical depth at air mass $\mathrm{m}$. For clear atmosphere $\mathrm{T}_{\mathrm{LK}}=2$. The optical air mass can be calculated from the Kasten and Young (1989) equation as:

$$
\left(\mathrm{P} / \mathrm{P}_{0}\right)=\exp (-\mathrm{z} / 8400)
$$

where $\alpha_{s}$ is the solar elevation angle and $z$ is the elevation of the station in $m$. The Rayleigh optical thickness is calculated from the following equations. If $m<20$, then:

$$
\delta_{\mathrm{r}}(\mathrm{m})=1 /\left(6.6296+1.7513 \mathrm{~m}-0.1202 \mathrm{~m}^{2}+0.0065 \mathrm{~m}^{3}-0.0003 \mathrm{~m}^{4}\right)
$$

If $m>20$, then:

$\delta_{\mathrm{r}}(\mathrm{m})=1 /(10.4+0.718 \mathrm{~m})$

The photosynthetic active irradiance (PARE) was also tested against the relevant extraterrestrial PAR irradiance $\left(\mathrm{PARE}_{0}\right)$. The photosynthetic photon flux densities $\left(\mu \mathrm{mol} \mathrm{s}^{-1} \mathrm{~m}^{-2}\right)$ are converted into irradiance units 
using the conversion factor of $4.57 \mu \mathrm{mol} \mathrm{s}^{-1} \mathrm{~W}^{-1}$ which was proposed by McCree (1972). The extraterrestrial PAR irradiance was estimated using Eq. (10) and setting the solar constant for the visible spectrum as 534.6 $\mathrm{W} / \mathrm{m}^{2}$ (Gueymard, 2004). All PAR data are within the above limits.
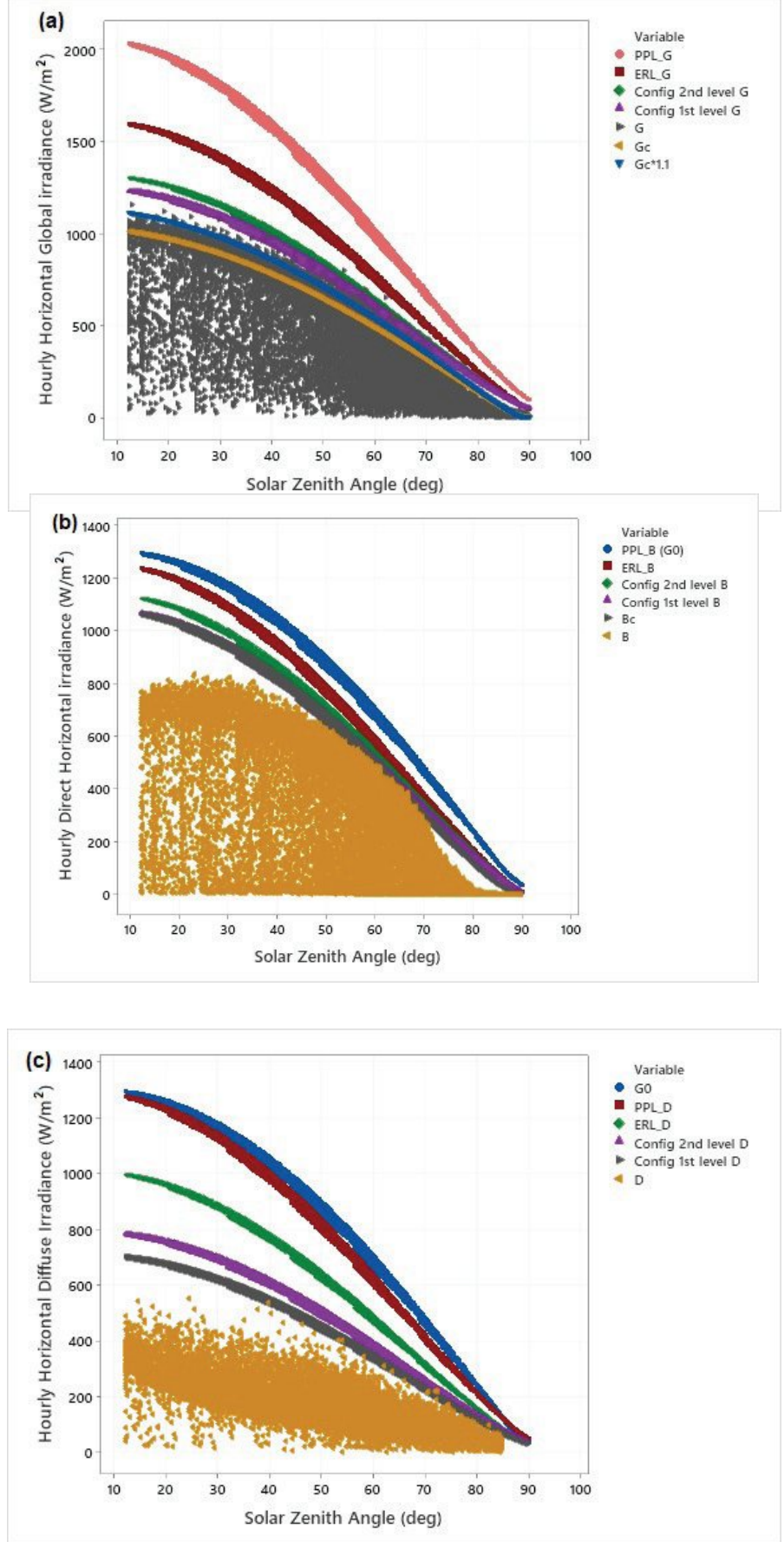

Figure (2). Hourly data of downwelling shortwave irradiances: a) Global b) Direct horizontal and c) Diffuse irradiances $\left(\mathrm{W} / \mathrm{m}^{2}\right)$ with their PPL, ERL and configurable limits. Estimated clear sky irradiances are also shown in the graphs. 
The comparison tests are concentrated on the ratios of $\mathrm{k}_{\mathrm{b}}, \mathrm{k}_{\mathrm{d}}$ and $\mathrm{k}_{\mathrm{t}}$. The ratio of horizontal beam irradiance (B) to the global irradiance $G$ is defined as $k_{b} ; k_{d}$ is the fraction of diffuse irradiance (D) to the global $(G) ; k_{t}$ is the clearness index, i.e., the ratio of global irradiance to the extraterrestrial irradiance:

$$
\begin{aligned}
& \mathrm{k}_{\mathrm{b}}=\mathrm{B} / \mathrm{G} \\
& \mathrm{k}_{\mathrm{d}}=\mathrm{D} / \mathrm{G} \\
& \mathrm{k}_{\mathrm{t}}=\mathrm{G} / \mathrm{G}_{0}
\end{aligned}
$$

The ratio $k_{b}$ is always lower than 1 . The upper bound of the $k_{d}$ ratio is 1 , although it can be slightly higher than 1 (i.e., 1.15). This usually occurs in the morning after sunrise or in the afternoon before sunset when the solar elevation angle is low and the diffuse irradiance is slightly higher than that of global irradiance due to the cosine effect of the lower sun angles. Therefore, to avoid this problem, cases of diffuse irradiances below $5^{0}$ of sun elevation angle were excluded from the data set (Younes et al., 2005). Only few observations are considered invalid when low $\mathrm{k}_{\mathrm{d}}$ values are associated with low $\mathrm{k}_{\mathrm{t}}$ values. This occurs when the sensor is covered with environmental debris.

Another quality control test is the step test. This test is based on time consistency which compares the difference between successive measurements. If the difference exceeds an allowed value, then both observations are flagged as suspects. Estevez et al. (2011) proposed the following values for different variables: for hourly global irradiance the limit is $555 \mathrm{~W} / \mathrm{m}^{2}$ and for hourly temperature it is set to $7^{\circ} \mathrm{C}$, while for relative humidity the suggested value is $45 \%$. The data set confirms the limits of the above variables.

Finally, the persistency test was applied to check the variability of the measurements. When a sensor fails, it will often report a constant value. No days have been detected with a constant value.

\subsubsection{Quality control of daily values}

The quality control process was also extended to the daily sums of global solar irradiation and daily sunshine duration values. Firstly, the daily values of Global irradiation $\left(G_{d}\right)$, were checked against the extraterrestrial daily irradiation $\left(G_{0 d}\right)$. The daily values of $G_{d}$ should be lower than $G_{0 \mathrm{~d}}$, but they should be higher than the lower limit of $0.03 \mathrm{G}_{0 \mathrm{~d}}$ during overcast conditions (Scharmer and Greif, 2000). As can be seen in Fig. 3, $G_{d}$ is lower than the upper limit of $G_{0 d}$ and it is generally higher than the lower limit.

The second test is a comparison test between the extreme values of daily sums of global irradiation and the respective daily sums on clear days. The daily sums should only exceed the clear sky values with high atmospheric transparency by a small amount, i.e., $\mathrm{G}_{\mathrm{d}}<1.1 \mathrm{G}_{\mathrm{cd}}$. The daily clear irradiation was estimated using two empirical models. The first model was proposed by Hottel (1976) which combines the beam transmittance and the diffuse expression developed by Lui and Jordan (1960).

$$
\begin{aligned}
& \mathrm{B}_{\mathrm{nc}}=\left(\mathrm{G}_{0 \mathrm{n}} / \cos \theta_{z}\right)\left(\mathrm{k}_{0}+\mathrm{k}_{1} \exp \left(-\mathrm{k}_{2} / \cos \theta_{z}\right)\right) \\
& \mathrm{D}_{\mathrm{c}}=\mathrm{G}_{0 \mathrm{n}} \times 0.2710-0.2939 \times \mathrm{B}_{\mathrm{n}} \cos \theta_{z} \ldots \ldots \ldots \ldots \ldots
\end{aligned}
$$

where $\mathrm{B}_{\mathrm{nc}}$ is the normal beam clear sky irradiance, $\mathrm{D}_{\mathrm{c}}$ is the diffuse clear sky irradiance and the parameters $\mathrm{k}_{0}, \mathrm{k}_{1}$ and $\mathrm{k}_{2}$ are functions of the site elevation only.

The second model was proposed by Haurwitz (1945) and is a function of the zenith angle. This model was tested by Ianetz (2007) in Israel showing high performance. The equation involved in the said model is shown below:

$$
\mathrm{G}_{\mathrm{c}}=1098 \cos \theta_{\mathrm{z}} \times \exp \left(-0.057 / \cos \theta_{\mathrm{z}}\right)
$$

The third test compares the monthly mean daily values with those at nearby stations of Athalassa, Mathiatis two inland locations and Larnaca a coastal one (Kalogirou et al., 2017). Almost similar values of 
monthly daily means are observed at the four stations, although the measurement period of the two stations is different from that in the current study. Larnaca shows the higher values from the other stations. The rest three inland stations have a similar trend. It has to be noted that Farmakas and Mathiatis have common period of measurements.

Finally, the daily sums of sunshine duration $\left(\mathrm{S}_{\mathrm{d}}\right)$ should not exceed the daylength $\left(\mathrm{S}_{0 \mathrm{~d}}\right)$, i.e., $\mathrm{S}_{\mathrm{d}}<\mathrm{S}_{0 \mathrm{~d}}$. All the values passed this test.

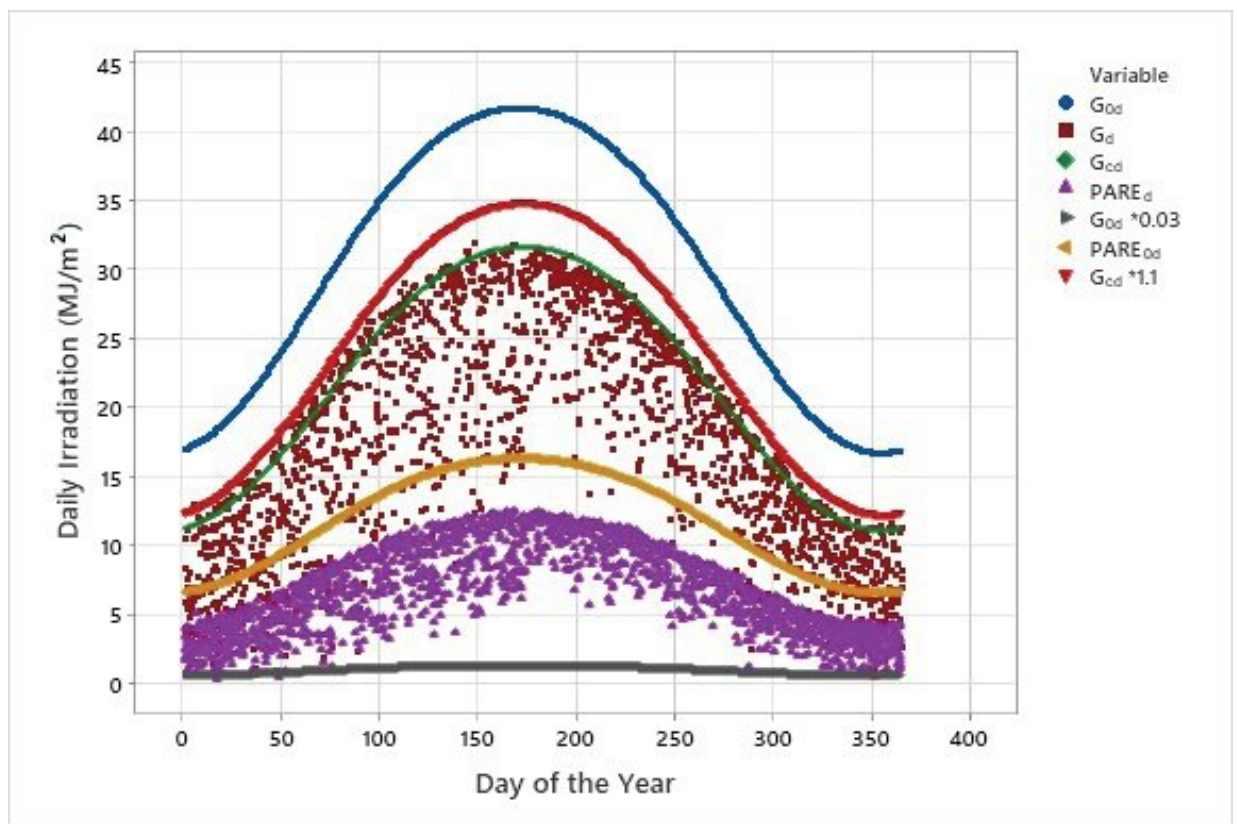

Figure (3). Daily totals of global irradiation $\left(\mathrm{MJ} / \mathrm{m}^{2}\right)$ compared to the respective extraterrestrial and clear-sky irradiation. The daily totals of PAR and their extraterrestrial values are also shown on the graph.

The time series plots of the daily irradiation in $\mathrm{MJ} / \mathrm{m}^{2}$ of all the radiation components are shown in Figure 4. The similarities of diffuse and PARE are evident. Both variables range mainly between 2 and $12 \mathrm{MJ} / \mathrm{m}^{2}$. The highest horizontal direct irradiation reaches the value of $24 \mathrm{MJ} / \mathrm{m}^{2}$, while the highest daily recorded global radiation is $31.9 \mathrm{MJ} / \mathrm{m}^{2}$.

\section{RESULTS AND DISCUSSION}

\subsection{Hourly values}

The variation of the hourly measured and estimated values of the shortwave radiation components with the solar zenith angle and the associated clearness index is illustrated in Fig. 5. High global and direct horizontal irradiances are associated with high clearness index, while higher diffuse irradiances are associated with lower clearness indices. Global irradiance is decreased almost exponentially with increasing SZA for a given $\mathrm{k}_{\mathrm{t}}$ interval. The top three layers of $\mathrm{k}_{\mathrm{t}}$ show the clear sky conditions. This relationship can be expressed as:

$$
\mathrm{G}=\mathrm{G}_{\max }\left(\cos \theta_{z}\right)^{\mathrm{b}}
$$

where $\mathrm{G}_{\max }$ is the maximum global irradiance for each $\mathrm{k}_{\mathrm{t}}$ interval and $\mathrm{b}$ describes how $\mathrm{G}$ changes with 
the cosine of SZA. The dependence of $\mathrm{G}_{\max }$ on $\mathrm{k}_{\mathrm{t}}$ can be described by the cubic equation as:

$$
\mathrm{G}_{\max }=96.36-283.17 \mathrm{k}_{\mathrm{t}}+5.06652 \mathrm{k}_{\mathrm{t}}^{2}-4298.54 \mathrm{k}_{\mathrm{t}}^{3}
$$

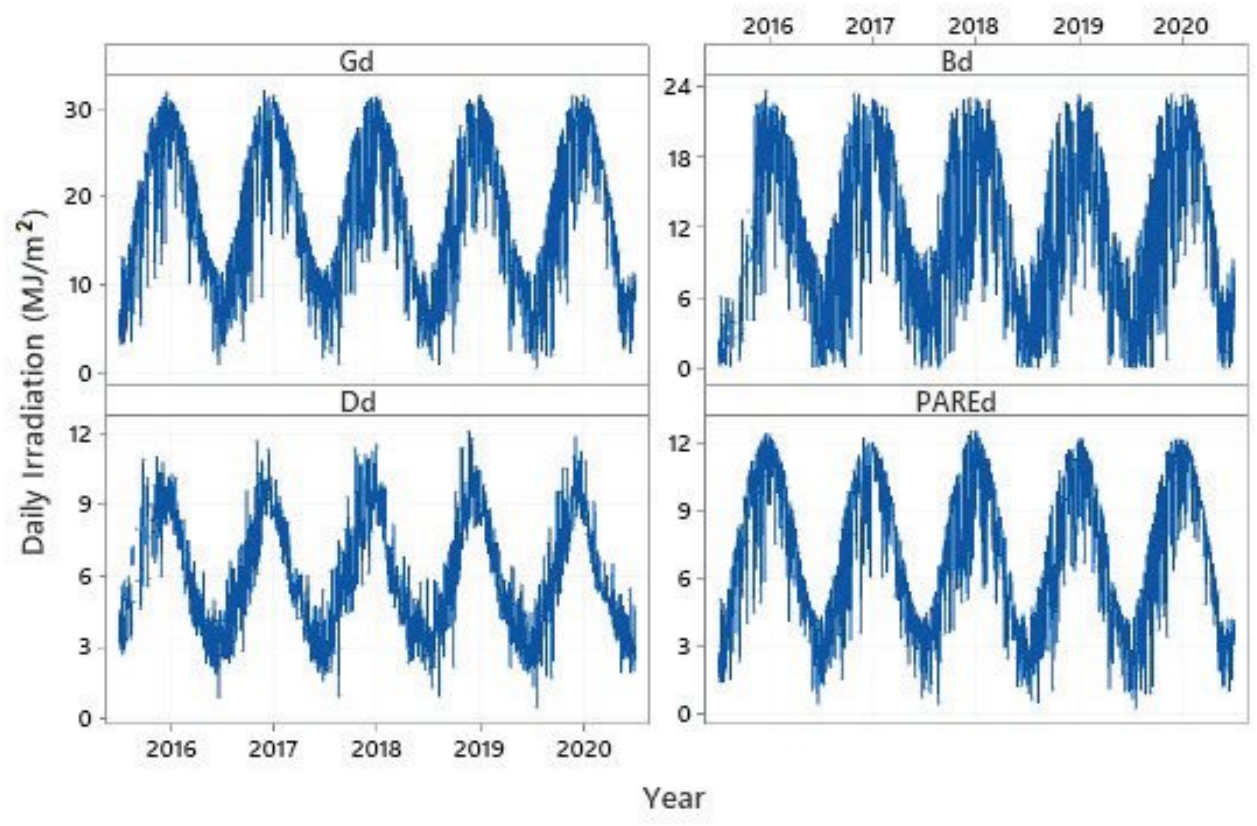

Figure (4). Time series plots of the daily irradiation values of a) Global, b) Direct horizontal, c) Diffuse and d) PARE in $\mathrm{MJ} / \mathrm{m}^{2}$.

In the second step, $\mathrm{b}$ was obtained from analyzing the relationship between hourly $\mathrm{G}$ and the cosine of zenith angle using a non-linear statistical method. The value of $b$ was estimated at 0.93 with a standard error of 0.029 .

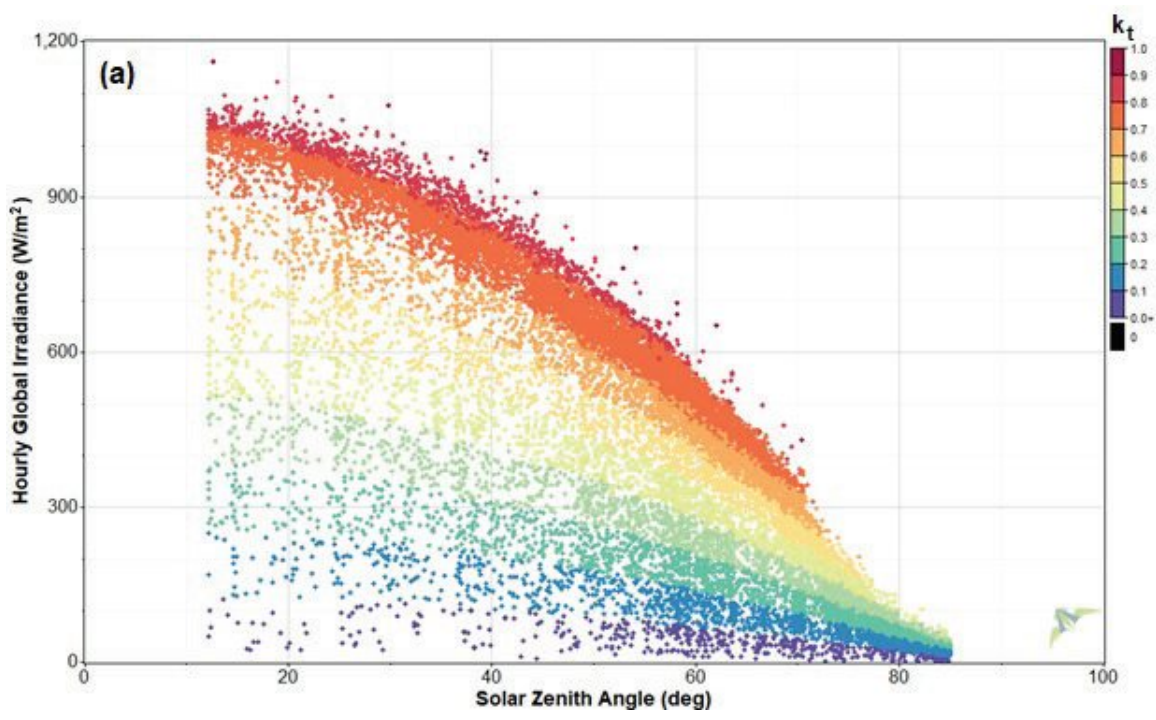

Figure (5). Global solar irradiances as a function of solar zenith angle and clearness index. 


\subsubsection{Monthly average hourly irradiances}

The daily variation of the average hourly global irradiance is shown in Fig. 6. The figure shows that the hourly average global irradiance fluctuates between $390 \mathrm{~W} / \mathrm{m}^{2}$ in January and $940 \mathrm{~W} / \mathrm{m}^{2}$ in July at local noon. The respective ranges of direct horizontal irradiances are $225 \mathrm{~W} / \mathrm{m}^{2}$ and $650 \mathrm{~W} / \mathrm{m}^{2}$, while the diffuse irradiances fluctuate between $160 \mathrm{~W} / \mathrm{m}^{2}$ and $330 \mathrm{~W} / \mathrm{m}^{2}$. The curves of each month of global irradiances are symmetrical around the local noon. As it can be seen, the curves can be classified in 5 groups with similarities with respect to their variation. Starting from the top curves, the first group represents the summer months (June, July and August) and slightly below it is the second with the months of April, May and September. March and October consists the third group which is followed by the group of the months of February and November and the last group is the winter months of January and December.

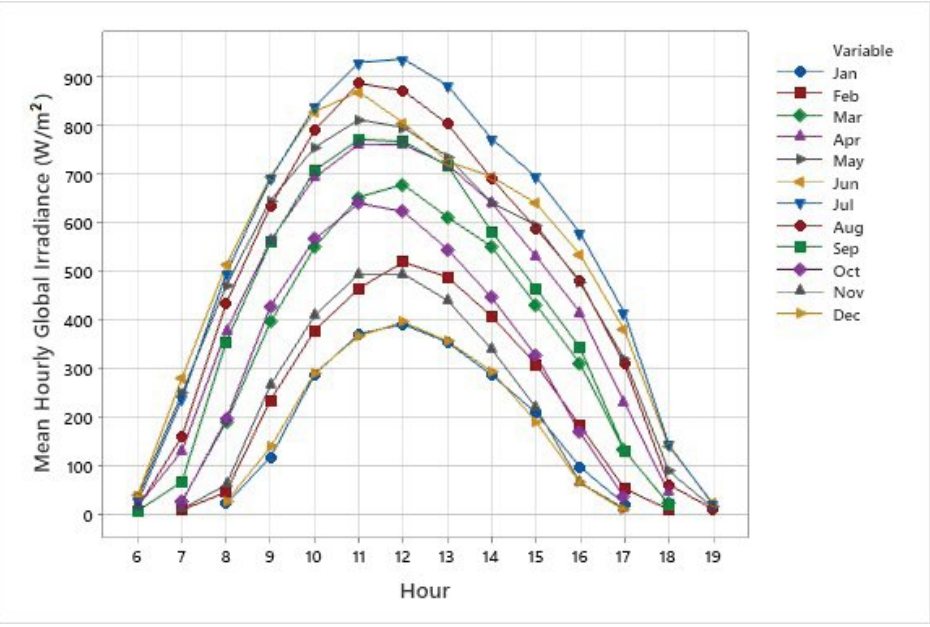

Figure (6). Daily variation of the average hourly global irradiance $\left(\mathrm{W} / \mathrm{m}^{2}\right)$.

In Figure 7, Monthly Mean Hourly (MMH) values of global, direct and diffuse irradiances on horizontal surfaces in $\mathrm{W} / \mathrm{m}^{2}$ are shown for Farmakas by means of isoline diagrams. These graphs show representative values of irradiances for each hour of every month of the year. July is the month with maximum values of all radiation components. At noon, $\mathrm{MMH}$ of global irradiance is greater than $700 \mathrm{~W} / \mathrm{m}^{2}$, and the direct horizontal irradiance is greater than $500 \mathrm{~W} / \mathrm{m}^{2}$. The respective diffuse irradiance is greater than $200 \mathrm{~W} / \mathrm{m}^{2}$. At noon, values of about 400 and $500 \mathrm{~W} / \mathrm{m}^{2}$ are obtained for winter months for global irradiances.

The variability of the four shortwave hourly irradiances is demonstrated with the graph of boxplots for each month of the year. The boxplot presents the median and the Interquartile Range (IQR) as well as the outliers (asterisks) of each variable (Fig. 8). The smooth line represents the mean values of irradiances for each month of the year. As it can be seen no outliers are observed for the hourly global irradiances, while outliers for the direct irradiances are observed only in January. On the other hand, outliers at the higher values are observed in almost all the months of the year for the estimated hourly diffuse irradiances. The highest monthly mean values of the hourly irradiances are recorded in June or July and the lowest in December or January. The monthly mean hourly global irradiances range between 210 and $550 \mathrm{~W} / \mathrm{m}^{2}$, while those for the direct horizontal irradiances range between 110 and $380 \mathrm{~W} / \mathrm{m}^{2}$. The monthly mean hourly values of diffuse irradiances are relatively constant throughout the year and they range mainly between 100 and $200 \mathrm{~W} / \mathrm{m}^{2}$. 

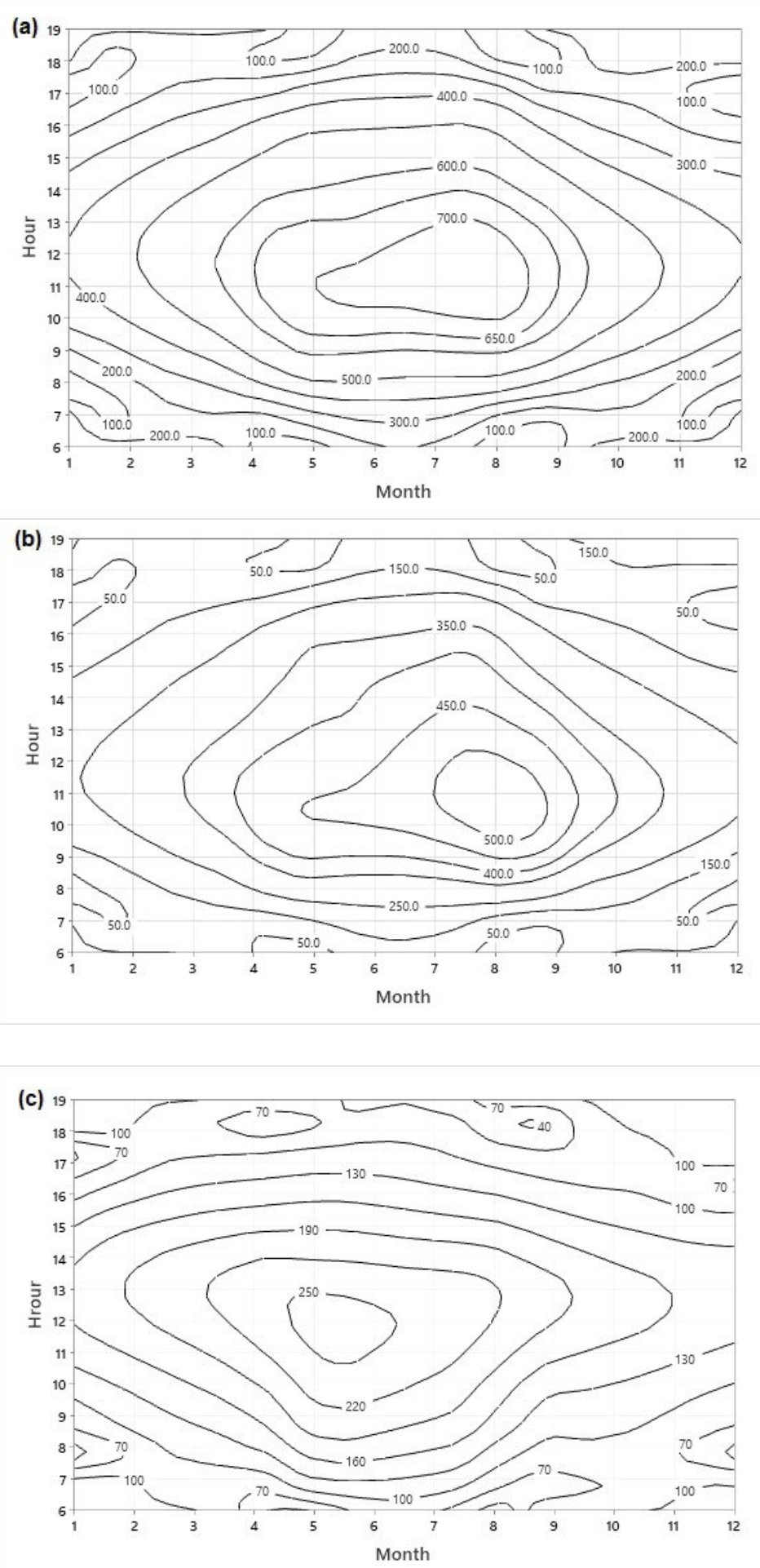

Figure (7. a) Isoline diagrams of monthly mean hourly global, b) direct horizontal and c) diffuse irradiance values $\left(\mathrm{W} / \mathrm{m}^{2}\right)$. 


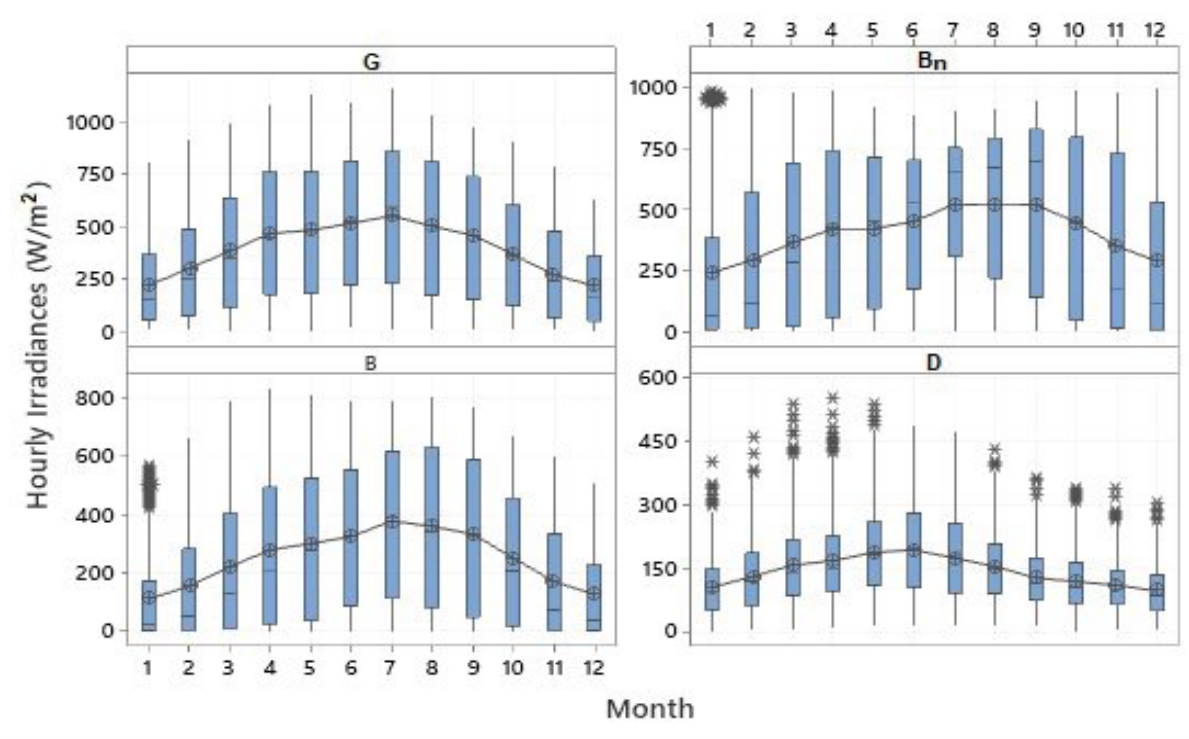

Figure (8). Boxplots of hourly a) Global, b) Direct Normal, c) Direct Horizontal and d) Diffuse irradiances $\left(\mathrm{W} / \mathrm{m}^{2}\right)$ for each month of the year at Farmakas. The symbol of the median values is presented as (-) in the boxplot. The asterisks denote the outliers. The smooth line represents the mean values of each month.

The annual Cumulative Density Curves (CDF) for each variable are shown in Fig. 9. The percentiles of each variable can be obtained from the graph. For example, the 50 percentile represents a value of $380 \mathrm{~W} /$ $\mathrm{m}^{2}$ for global irradiances, $400 \mathrm{~W} / \mathrm{m}^{2}$ for direct normal, $200 \mathrm{~W} / \mathrm{m}^{2}$ for direct horizontal and $135 \mathrm{~W} / \mathrm{m}^{2}$ for the diffuse irradiances. The figure indicates that in $50 \%$ of the hourly irradiances are less than above values. The reference line of $500 \mathrm{~W} / \mathrm{m}^{2}$ suggests that $\mathrm{Bn}$ is less than the reference value in $55 \%$ of the hourly values, while $\mathrm{G}$ and $\mathrm{B}$ are less than the reference value in about $60 \%$ and $80 \%$ of the cases, respectively.

The following linear relationship was developed between horizontal beam irradiance and global irradiance:

$$
\mathrm{B}=-49.02+0.777 \mathrm{G} \quad \mathrm{R}^{2}=0.94
$$

Strong relationship was also established between PARE and global irradiance:

$$
\text { PARE }=-0.543+0.392 \mathrm{G} \quad \mathrm{R}^{2}=0.99
$$

\subsubsection{Hourly Indices}

The definition of various hourly indices was introduced in the section of quality control process. The monthly variability of each index is presented in Figure 10. Monthly means of $k_{t}$ range between 0.3 and 0.6 with the highest occurring in summer. Almost similar pattern is followed by the beam fraction $\left(\mathrm{k}_{\mathrm{b}}\right)$ and the normal beam clearness index $\left(\mathrm{k}_{\mathrm{bn}}\right)$ but with slight different range of ratios. On the other hand, the diffuse fraction $\left(\mathrm{k}_{\mathrm{d}}\right)$ shows higher values in winter and the lowest in summer. However, $\mathrm{k}_{\mathrm{d}}$ has a lot of outliers in the summer months, since few days with clouds can cause this variability. The isolines diagram for $\mathrm{MMH}$ values of $\mathrm{k}_{\mathrm{t}}$ is shown in Figure 11. As can be seen, values higher than 0.65 are obtained for the period of MaySeptember, indicating a high percentage of clear days. 


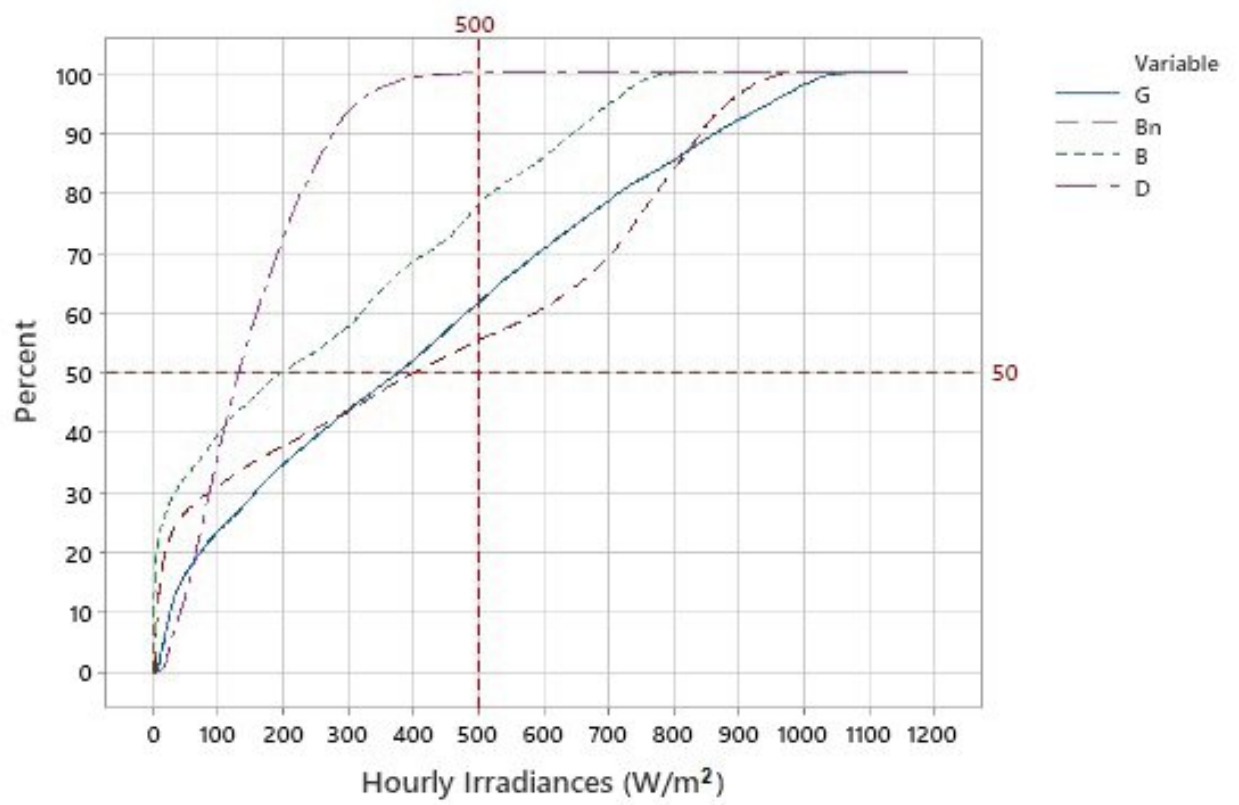

Figure (9). Annual Cumulative Density Function (CDF) curves of the solar radiation components (W/m²).

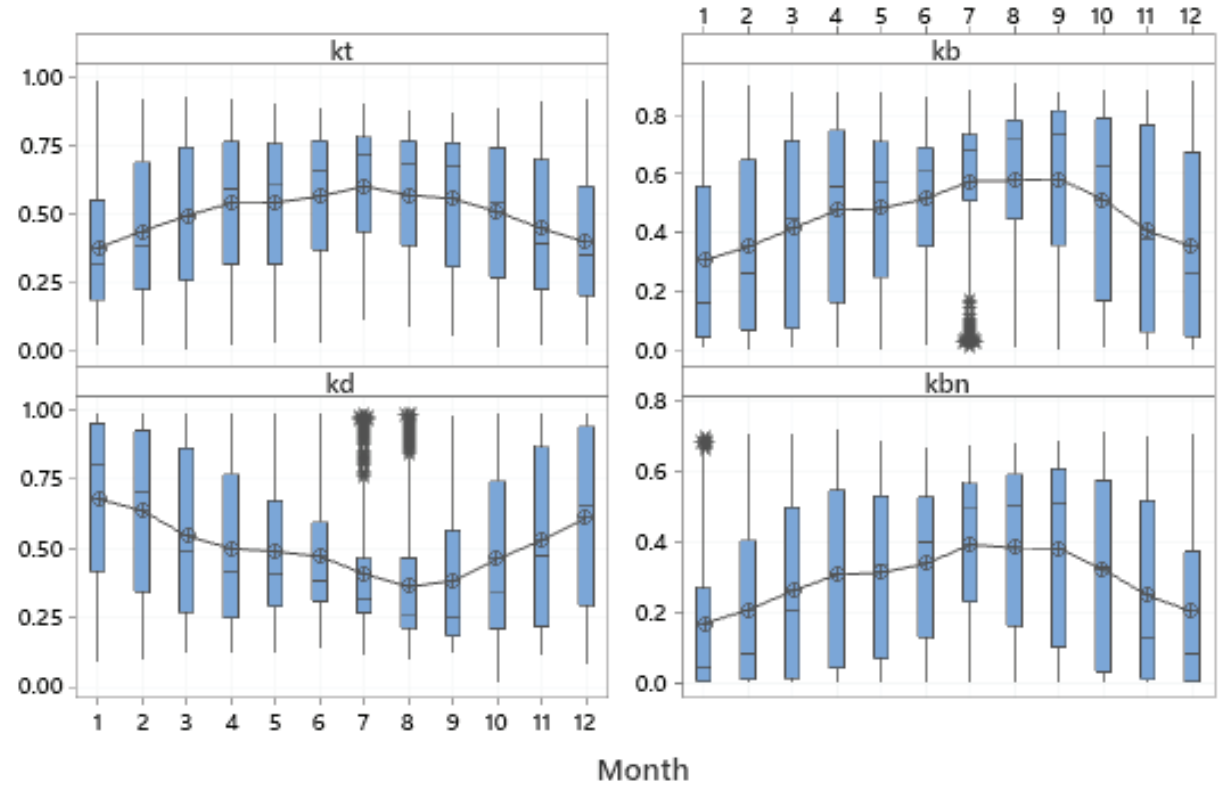

Figure (10). Monthly variability of each hourly index. 


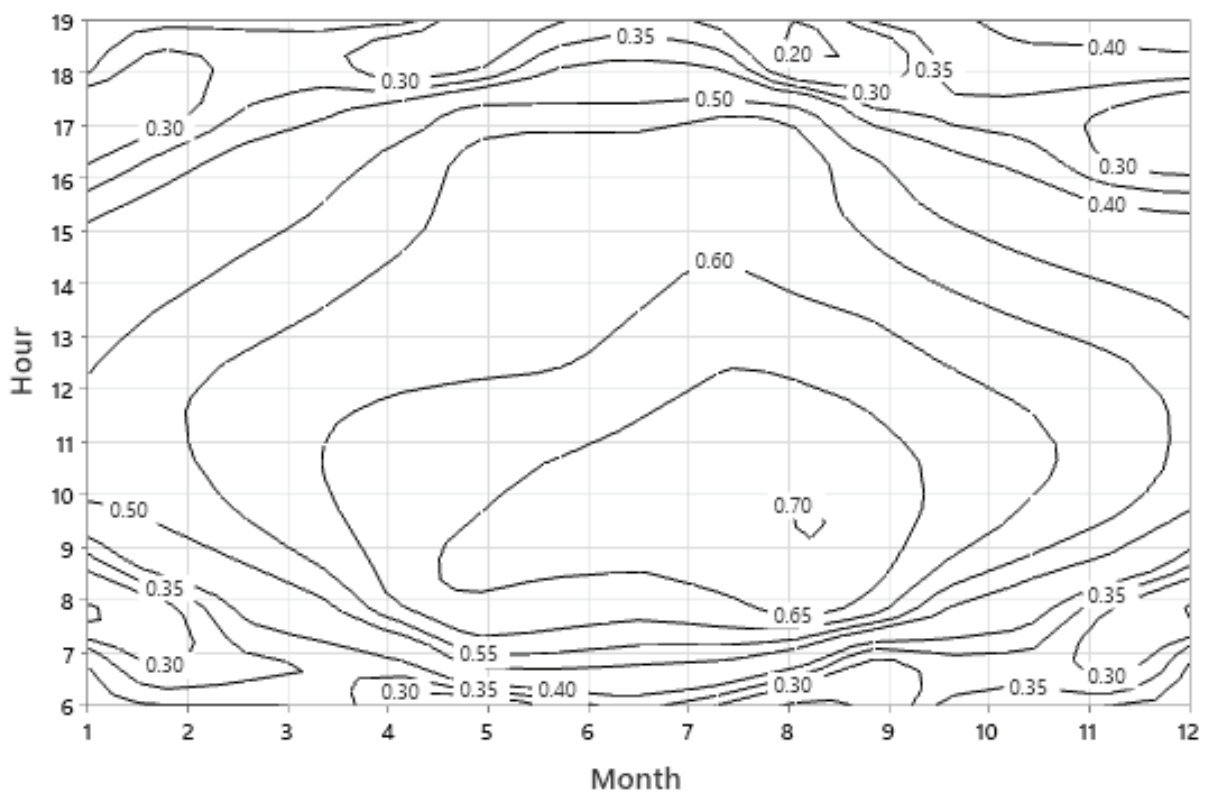

Figure (11). Isolines diagram for Monthly Mean Hourly (MMH) values of clearness index $\left(\mathbf{k}_{\mathrm{t}}\right)$

The relationships between the above indices and the clearness index are illustrated in Fig. 12. The diffuse clearness index shows its higher variability in the range of $0.35<\mathrm{k}_{\mathrm{t}}<0.65$, i.e., during partly cloudy conditions.

(a)

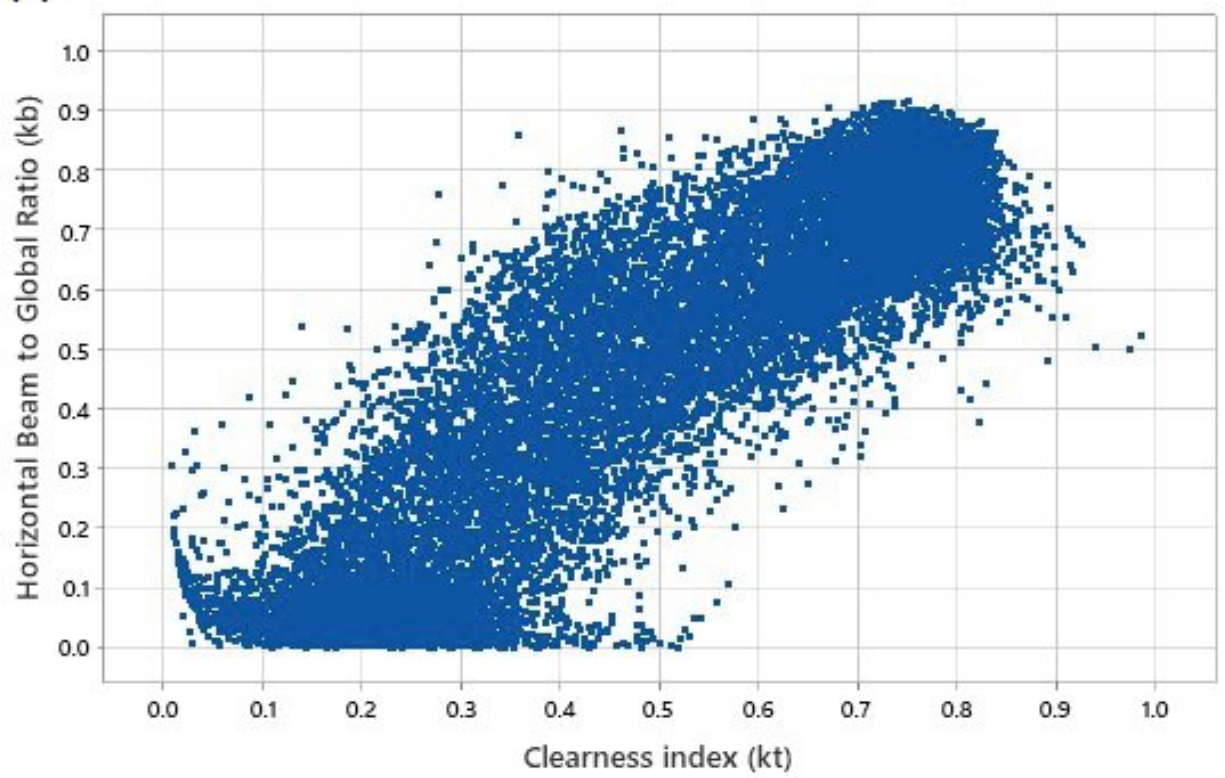




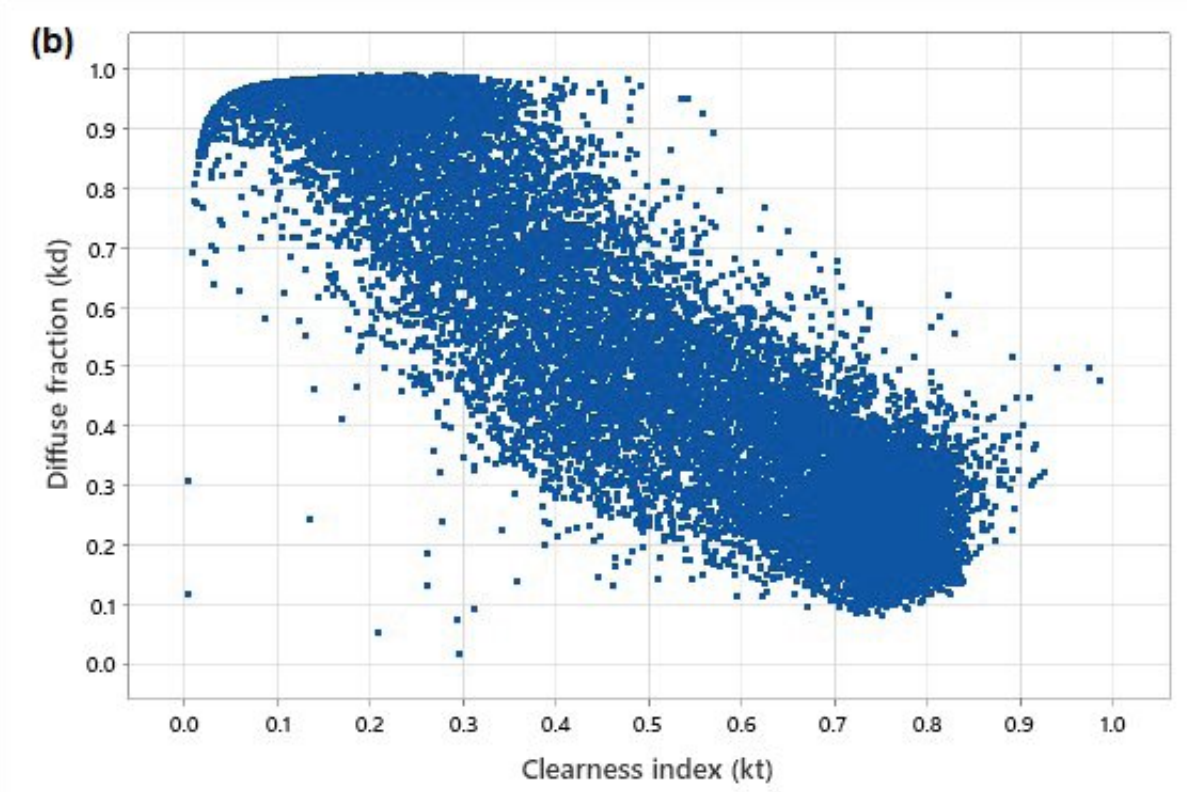

Figure (12. a) Horizontal beam fraction $\left(k_{b}\right)$, and b) Diffuse fraction $\left(k_{d}\right)$ as a function of clearness index $\left(\mathbf{k}_{\mathrm{t}}\right)$.

A correlation between the hourly direct horizontal irradiance and clearness index is presented in Fig. 13. A second degree polynomial curve has been obtained as the best fitting curve as shown in Fig. 13 (thick solid line). The mathematical expression for the fitting curve is:

$\mathrm{B}=55.16-556.9 \mathrm{k}_{\mathrm{t}}+1561 \mathrm{k}_{\mathrm{t}}^{2} \quad \mathrm{R}^{2}=0.896$

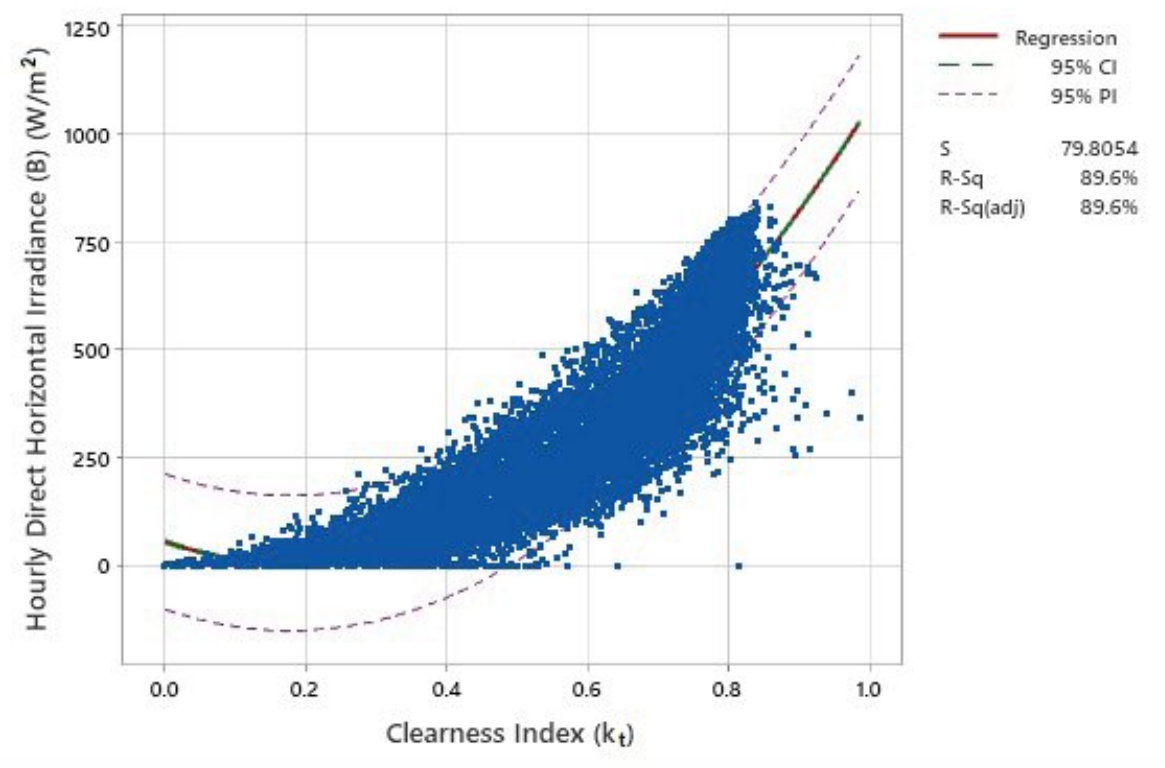

Figure (13). Correlation between the hourly direct horizontal irradiance (B) and clearness index ( $\left.k_{t}\right)$ 


\subsubsection{Modeling of hourly diffuse solar fraction with multiple predictors}

The generic multiple predictor logistic model developed by Ridley et al. (2010) known as BRL (BolandRidley-Lauret) model was used to estimate the diffuse irradiance. The model is a function of clearness index $\left(\mathrm{k}_{\mathrm{t}}\right)$, the apparent solar time (AST), solar altitude $\left(\alpha_{\mathrm{s}}\right)$, daily clearness index $\left(\mathrm{K}_{\mathrm{T}}\right)$ and persistence $\Psi$ :

$$
\mathrm{k}_{\mathrm{d}}=1 /\left(1+\exp \left(-3.03+5.33 \mathrm{k}_{\mathrm{t}}+0.008 \mathrm{AST}-0.005 \alpha_{\mathrm{s}}+0.77 \mathrm{~K}_{\mathrm{T}}-0.2 \psi\right)\right)
$$

The 'persistence' term is an average of both a lag and a lead of the clearness index for each hour of the day. The model was developed based on a four years 'training data set' (2016-2019) and the performance of the model was tested against the 'validation data set' of the year 2020, using the most popular statistical methods such as Mean Bias Error (MBE), Root Mean Square Error (RMSE), and the coefficient of determination $\left(\mathrm{R}^{2}\right)$. For higher modeling accuracy, these estimators should be closer to zero, and $\mathrm{R}^{2}$ should approach 1 . The estimated parameters shown in the above equation were close to those obtained by Ridley et al. (2010) at Adelaide of Australia, i.e., a location with similar climatic conditions to Cyprus. Then, the direct normal irradiance $\left(\mathrm{B}_{\mathrm{n} \_ \text {est }}\right)$ is calculated from the following equation:

$$
\mathrm{B}_{\mathrm{n}_{\text {est }}}=\left(\mathrm{G}-\mathrm{k}_{\mathrm{d}} \mathrm{G}\right) / \cos \theta_{\mathrm{z}}
$$

The statistical measures of the estimated errors between the estimated direct normal irradiance $\left(\mathrm{E}_{\mathrm{i}}\right)$ and the measured one $\left(\mathrm{M}_{\mathrm{i}}\right)$ are given by the following equations:

$$
\begin{aligned}
& \operatorname{MBE}=\frac{1}{\mathrm{n}} \sum_{\mathrm{i}=1}^{\mathrm{n}}\left(\mathrm{E}_{\mathrm{i}}-\mathrm{M}_{\mathrm{i}}\right) \ldots \ldots \ldots \\
& \operatorname{RMSE}=\sqrt{\frac{1}{\mathrm{n}} \sum_{\mathrm{i}=1}^{\mathrm{n}}\left(\mathrm{E}_{\mathrm{i}}-\mathrm{M}_{\mathrm{i}}\right)^{2}}
\end{aligned}
$$

Figure 14 shows the BRL diffuse fraction model fit (Eq. (31)) to Farmakas data for the year 2020. As shown the fitting of the spread of the data is much better than a simple line.

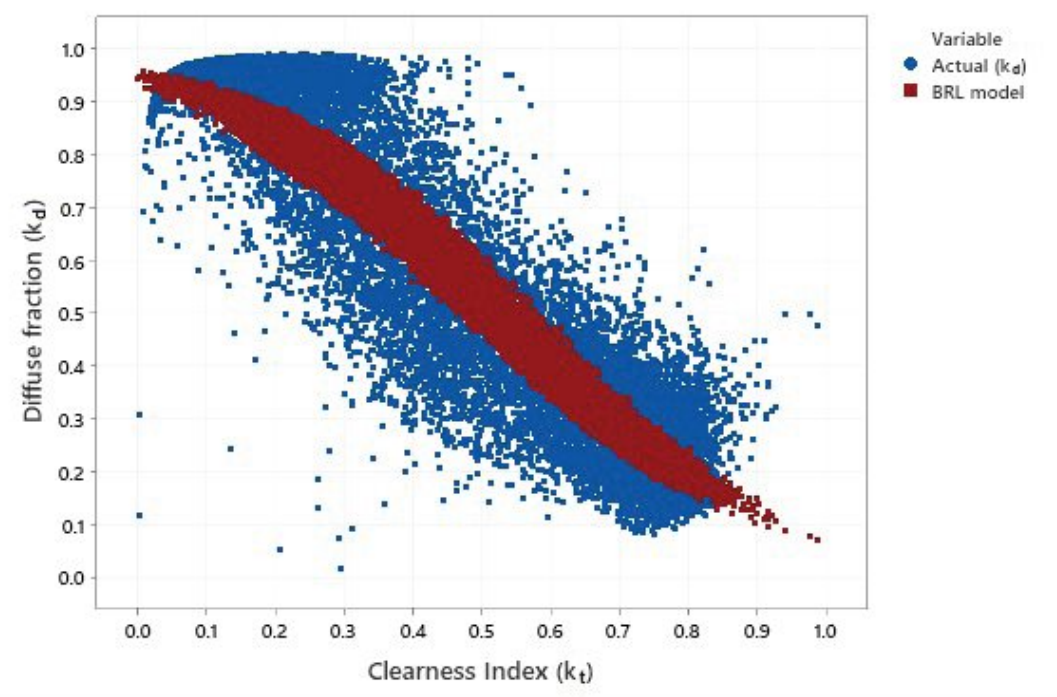

Figure (14). The BRL diffuse fraction model fit to the study station data (validation data set of the year 2020). 


\subsection{Daily values}

Daily solar radiation components have been analyzed and compared in this study. Figure 4 shows the temporal evolution of daily irradiation components at Farmakas. Data reveal a common evolution shape with maxima in summer and minima in winter, due to the daily minimum solar zenith angle and day-length (astronomical factors) variation during the year. Large fluctuations are occurred in spring and autumn during the transition from cold to warm weather and vice versa. The maximum of daily global solar horizontal irradiation is reached in June or July and it is almost $32 \mathrm{MJ} / \mathrm{m}^{2}$. The daily maximum of beam normal irradiation is slightly higher $\left(33 \mathrm{MJ} / \mathrm{m}^{2}\right)$, while the maximum horizontal daily irradiation is $23.5 \mathrm{MJ} / \mathrm{m}^{2}$. The maximum daily diffuse irradiation is around $12 \mathrm{MJ} / \mathrm{m}^{2}$ and the maximum daily PARE is slightly higher $\left(12.5 \mathrm{MJ} / \mathrm{m}^{2}\right)$.

Table 3 shows the mean daily values and their standard deviations of all the radiation components for each month of the year for the whole period of measurements. The variability of the daily values of the four radiation components is also demonstrated through the boxplots of each month of the year (Figure 15). The boxplot presents the mean and median, the IQR as well as the outliers of each variable. The smooth curve represents the mean daily values of each month of the year. As indicated from the length of the boxplots, the spring season shows the greatest variability. Outliers are observed mainly in July, although the daily diffuse irradiation shows outliers in almost all the months of the year. The monthly mean daily values of the three radiation components are almost similar to those obtained from Athalassa and Larnaca (Pashiardis et al., 2017). A quadratic equation describes the relationship between the daily beam horizontal irradiation $\left(B_{d}\right)$ and the daily global irradiation $\left(G_{d}\right)$ :

$$
\mathrm{B}_{\mathrm{d}}=-1.997+0.725 \mathrm{G}_{\mathrm{d}}+0.002 \mathrm{G}_{\mathrm{d}}^{2} \quad \mathrm{R}^{2}=0.93
$$

Almost similar equation was obtained for Athalassa and Larnaca (Pashiardis et al., 2017).

Table (3). Mean daily and maximum values and the standard deviations of all the radiation components for each month of the year and for the whole period of measurements $\left(\mathrm{MJ} / \mathrm{m}^{2}\right)$.

\begin{tabular}{|c|c|c|c|c|c|c|c|c|c|c|c|c|c|c|c|}
\hline & \multicolumn{3}{|c|}{$\mathrm{G}_{\mathrm{d}}$} & \multicolumn{3}{|c|}{$\mathrm{B}_{\text {nd }}$} & \multicolumn{3}{c|}{$\mathrm{B}_{\mathrm{d}}$} & \multicolumn{3}{|c|}{$\mathrm{D}_{\mathrm{d}}$} & \multicolumn{3}{c|}{ PARE $_{\mathrm{d}}$} \\
\hline Month & Mean & StDev & Max & Mean & StDev & Max & Mean & StDev & Max & Mean & StDev & Max & Mean & StDev & Max \\
\hline 1 & 7.8 & 3.28 & 14.5 & 8.6 & 6.83 & 23.4 & 4.0 & 3.23 & 11.6 & 3.5 & 1.03 & 6.6 & 3.1 & 1.19 & 5.4 \\
2 & 11.1 & 4.11 & 18.8 & 10.9 & 7.26 & 27.1 & 5.8 & 3.99 & 14.7 & 4.7 & 1.28 & 7.4 & 4.4 & 1.50 & 7.2 \\
3 & 16.4 & 5.19 & 24.9 & 15.8 & 8.76 & 31.0 & 9.7 & 5.50 & 20.3 & 6.1 & 1.55 & 10.9 & 6.3 & 1.89 & 9.5 \\
4 & 21.2 & 5.80 & 28.9 & 19.1 & 8.89 & 33.3 & 12.9 & 6.31 & 23.3 & 7.3 & 1.55 & 11.6 & 8.2 & 2.12 & 11.1 \\
5 & 23.9 & 5.75 & 31.9 & 21.0 & 7.54 & 32.2 & 15.0 & 5.80 & 23.3 & 8.8 & 1.26 & 12.1 & 9.3 & 2.16 & 12.1 \\
6 & 25.8 & 4.89 & 31.7 & 22.7 & 6.54 & 32.2 & 16.4 & 5.14 & 23.5 & 9.4 & 0.88 & 11.8 & 10.2 & 1.88 & 12.5 \\
7 & 27.6 & 3.29 & 31.4 & 26.3 & 4.79 & 31.4 & 19.1 & 3.77 & 23.2 & 8.5 & 0.85 & 11.4 & 10.9 & 1.23 & 12.4 \\
8 & 24.3 & 3.48 & 29.1 & 25.0 & 5.30 & 32.0 & 17.5 & 3.98 & 22.8 & 6.7 & 0.95 & 9.5 & 9.6 & 1.33 & 11.4 \\
9 & 19.8 & 3.79 & 25.3 & 22.6 & 5.95 & 30.2 & 14.5 & 4.09 & 20.5 & 5.2 & 0.70 & 7.5 & 7.8 & 1.40 & 9.9 \\
10 & 14.4 & 3.70 & 20.6 & 17.6 & 6.45 & 28.2 & 9.9 & 3.82 & 17.0 & 4.4 & 0.89 & 6.8 & 5.6 & 1.35 & 8.1 \\
11 & 10.1 & 2.95 & 15.5 & 13.3 & 6.48 & 25.4 & 6.5 & 3.24 & 13.0 & 3.6 & 0.82 & 5.7 & 3.9 & 1.07 & 5.9 \\
12 & 7.7 & 2.74 & 11.8 & 10.3 & 6.68 & 22.2 & 4.5 & 2.97 & 9.7 & 3.1 & 0.86 & 5.8 & 3.0 & 0.98 & 4.5 \\
\hline Year & 17.5 & 8.10 & 31.9 & 17.9 & 8.93 & 33.3 & 11.4 & 6.74 & 23.5 & 5.9 & 2.38 & 12.1 & 6.9 & 3.15 & 12.5 \\
\hline
\end{tabular}

The annual Cumulative Density Functions (CDF) for the daily values of all the radiation components are shown in Fig. 16. The figure indicates that in $80 \%$ of the year, the daily sums of diffuse irradiation is less than $8.5 \mathrm{MJ} / \mathrm{m}^{2}$, less than $18.9 \mathrm{MJ} / \mathrm{m}^{2}$ for direct horizontal, less than $26.5 \mathrm{MJ} / \mathrm{m}^{2}$ for global and less than 27.5 $\mathrm{MJ} / \mathrm{m}^{2}$ for direct normal irradiation. 


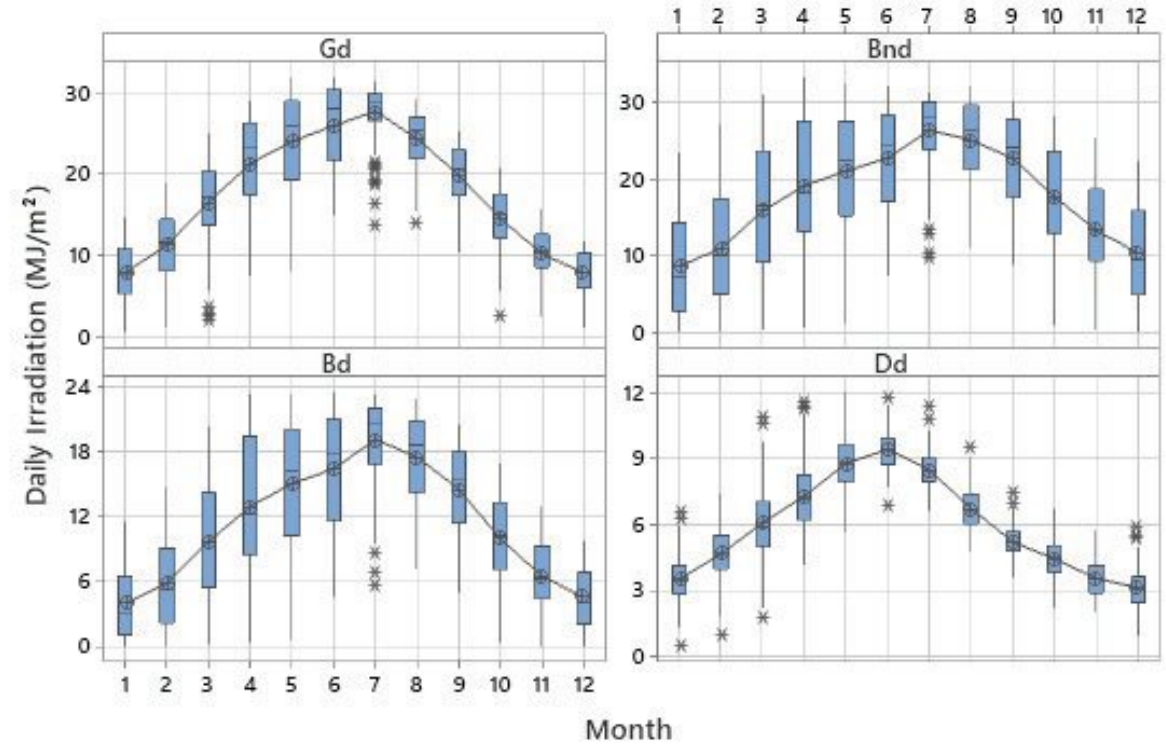

Figure (15). Boxplots of daily Global $\left(G_{d}\right)$, Direct normal $\left(B_{n d}\right)$, Direct horizontal $\left(B_{d}\right)$ and Diffuse $\left(D_{d}\right)$ irradiation $\left(\mathrm{MJ} / \mathrm{m}^{2}\right)$ for each month of the year. The smooth line represents the mean daily values of each month for each variable.

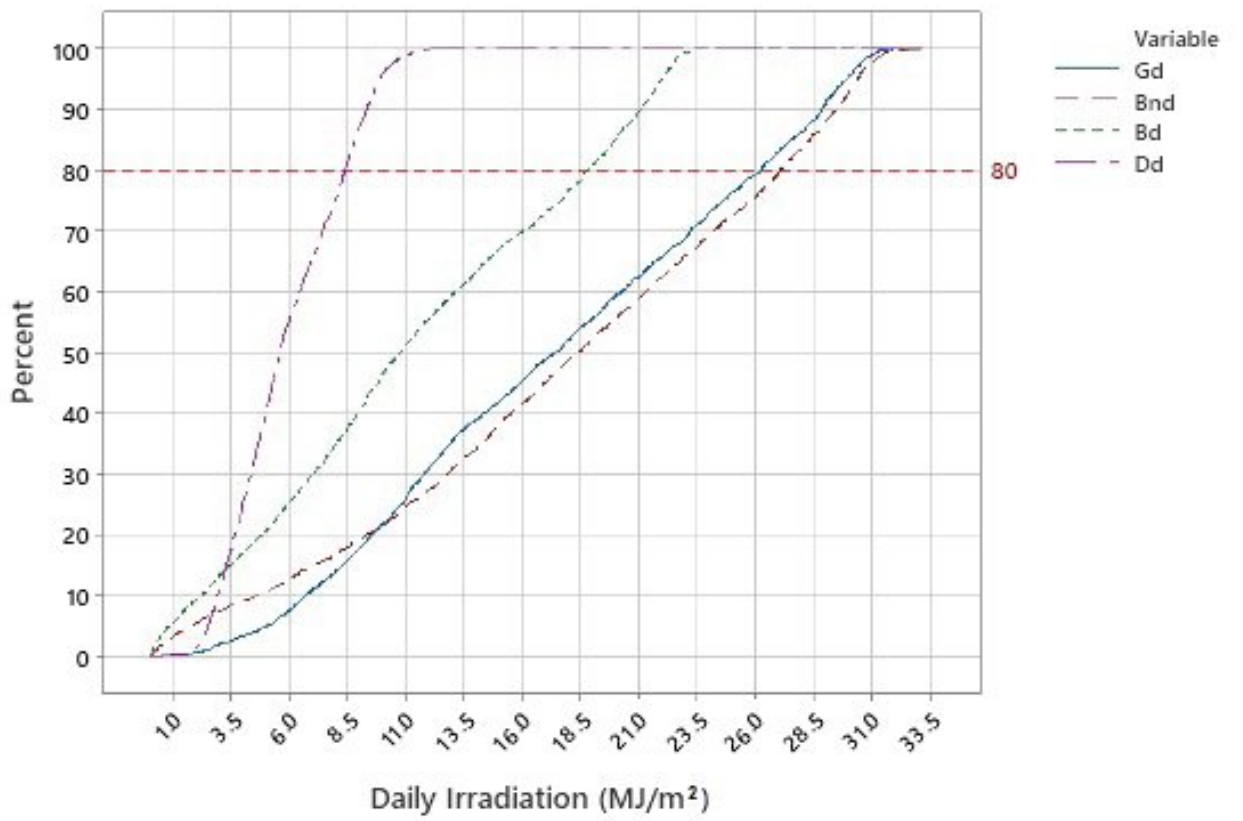

Figure (16). Annual Cumulative Frequency Density (CDF) curves of the daily Global $\left(G_{d}\right)$, Direct normal $\left(B_{n d}\right)$, Direct horizontal $\left(B_{d}\right)$ and Diffuse $\left(D_{d}\right)$ irradiation $\left(M J / m^{2}\right)$. 


\subsubsection{Daily Clearness index and relative sunshine duration}

The clearness index $\left(\mathrm{K}_{\mathrm{T}}\right)$, for a particular time interval, is defined as the ratio of the global radiation to the extraterrestrial radiation. It is an objective measure of the influence of cloud cover on the solar radiation flux. In this analysis, the range of clearness index values corresponding to three day types is defined as follows (Iqbal, 1983):

Clear days: $\mathrm{K}_{\mathrm{T}} \geq 0.65$

Partly cloudy days: $0.35<\mathrm{K}_{\mathrm{T}}<0.65$

Cloudy days: $\mathrm{K}_{\mathrm{T}} \leq 0.35$

The variation of the daily clearness index throughout the year is shown in Figure 17. It is clear that in summer months there are no cloudy days. The monthly statistics based on the daily clearness index values for Farmakas are reported in Table 4. Also listed in the table is the number of days according to the above classification for each month. The annual average of $\mathrm{K}_{\mathrm{T}}$ is 0.565 with a standard deviation of 0.161 . The average values of the daily clearness index range between 0.423 in January to 0.679 in July. The annual number of cloudy days is $44.4(12.16 \%)$, the respective number for partially cloudy days is 172.6 (47.29\%) and 148 days are classified as clear days representing the $40.55 \%$ of the annual number of days. As it can be seen, the summer months are classified mainly as clear days.

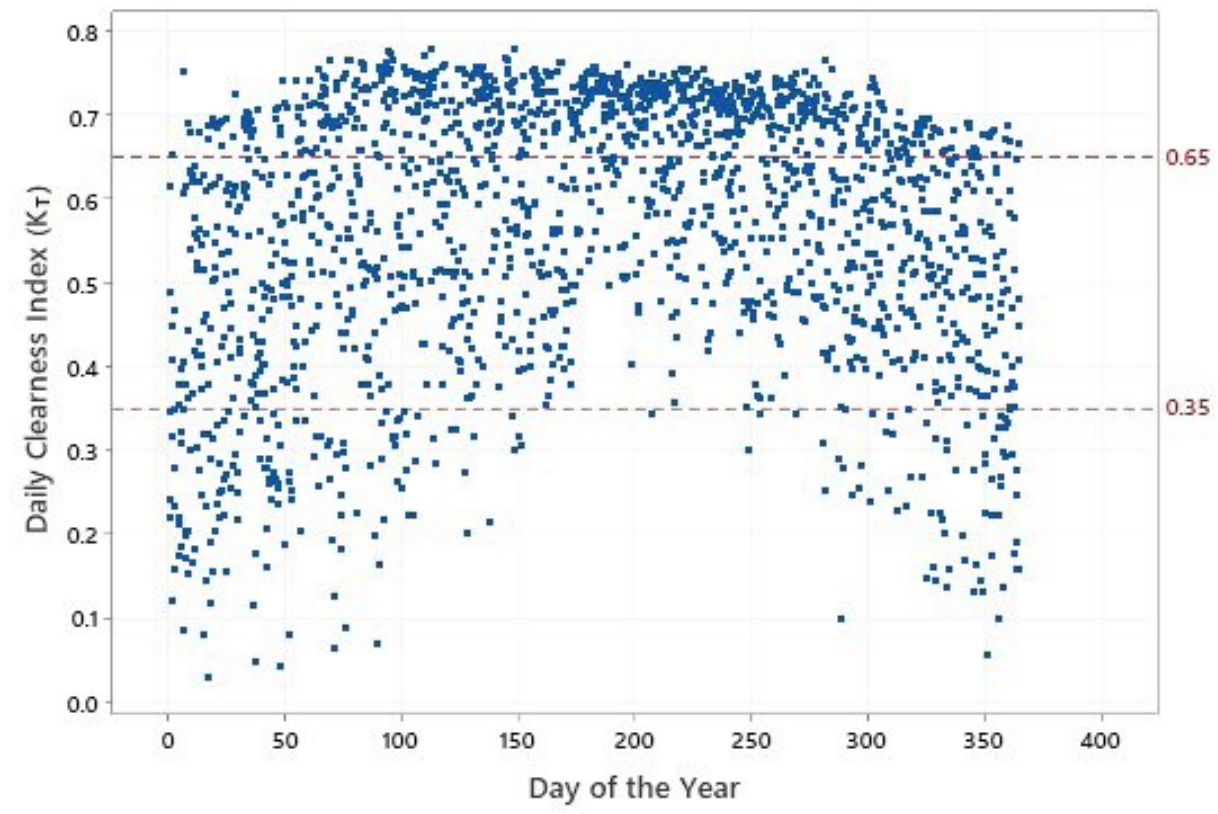

Figure (17). Daily clearness index $\left(\mathrm{K}_{\mathrm{T}}\right)$ for each day of the year. The reference lines indicate the thresholds for the classification of the days according to the value of $\mathrm{K}_{\mathrm{T}}$. 
Table 4. Monthly statistics of daily clearness index and number of days (N) according to the above classification for each month of the year.

\begin{tabular}{|c|c|c|c|c|c|c|c|c|c|c|c|c|c|c|c|c|}
\hline & \multicolumn{9}{|c|}{ Clearness Index $\left(\mathrm{K}_{\mathrm{T}}\right)$} & \multicolumn{2}{c|}{ Cloudy $\left(\mathrm{K}_{\mathrm{T}} \leq 0.35\right)$} & \multicolumn{2}{c|}{ Partly Cloudy $\left(0.35<\mathrm{K}_{\mathrm{T}}<0.65\right)$} & \multicolumn{2}{c|}{ Clear $\left(\mathrm{K}_{\mathrm{T}} \geq 0.65\right)$} \\
\hline Month & $\mathrm{N}$ & Mean & StDev & CV (\%) & Min & Q1 & Median & Q3 & Max & $\mathrm{N}$ & Percent & $\mathrm{N}$ & Percent & $\mathrm{N}$ & Percent \\
\hline 1 & 155 & 0.423 & 0.175 & 41.25 & 0.030 & 0.276 & 0.417 & 0.587 & 0.753 & 11.8 & 3.23 & 16.0 & 4.38 & 3.2 & 0.88 \\
2 & 140 & 0.481 & 0.173 & 35.86 & 0.043 & 0.353 & 0.491 & 0.632 & 0.741 & 6.8 & 1.86 & 14.8 & 4.05 & 6.4 & 1.75 \\
3 & 155 & 0.554 & 0.173 & 31.11 & 0.065 & 0.458 & 0.587 & 0.693 & 0.767 & 4.6 & 1.26 & 14.6 & 4.00 & 11.8 & 3.23 \\
4 & 150 & 0.590 & 0.158 & 26.74 & 0.219 & 0.493 & 0.634 & 0.726 & 0.778 & 4.2 & 1.15 & 12.0 & 3.29 & 13.8 & 3.78 \\
5 & 155 & 0.598 & 0.142 & 23.73 & 0.202 & 0.482 & 0.647 & 0.719 & 0.778 & 2.0 & 0.55 & 13.8 & 3.78 & 15.2 & 4.16 \\
6 & 150 & 0.622 & 0.118 & 18.93 & 0.354 & 0.522 & 0.675 & 0.728 & 0.763 & 0.0 & 0.00 & 13.8 & 3.78 & 16.2 & 4.44 \\
7 & 155 & 0.679 & 0.080 & 11.74 & 0.344 & 0.647 & 0.713 & 0.735 & 0.760 & 0.2 & 0.05 & 8.0 & 2.19 & 22.8 & 6.25 \\
8 & 155 & 0.651 & 0.091 & 13.91 & 0.358 & 0.590 & 0.679 & 0.723 & 0.756 & 0.0 & 0.00 & 12.0 & 3.29 & 19.0 & 5.21 \\
9 & 150 & 0.625 & 0.115 & 18.37 & 0.300 & 0.548 & 0.678 & 0.714 & 0.752 & 0.6 & 0.16 & 13.2 & 3.62 & 16.2 & 4.44 \\
10 & 155 & 0.575 & 0.134 & 23.34 & 0.100 & 0.483 & 0.599 & 0.694 & 0.766 & 2.2 & 0.60 & 16.8 & 4.60 & 12.0 & 3.29 \\
11 & 150 & 0.521 & 0.144 & 27.67 & 0.137 & 0.440 & 0.544 & 0.647 & 0.715 & 4.2 & 1.15 & 18.8 & 5.15 & 7.0 & 1.92 \\
12 & 155 & 0.456 & 0.161 & 35.42 & 0.056 & 0.350 & 0.471 & 0.599 & 0.691 & 7.8 & 2.14 & 18.8 & 5.15 & 4.4 & 1.21 \\
\hline Year & 1825 & 0.565 & 0.161 & 28.44 & 0.030 & 0.465 & 0.610 & 0.703 & 0.778 & 44.4 & 12.16 & 172.6 & 47.29 & 148.0 & 40.55 \\
\hline
\end{tabular}

Table 5. Monthly statistics of daily global $\left(G_{d}\right)$, normal beam $\left(B_{n d}\right)$, horizontal beam $\left(B_{d}\right)$ and diffuse $\left(D_{d}\right)$ radiation $\left(\mathrm{MJ} / \mathrm{m}^{2}\right)$ for clear, partially cloudy and cloudy days for Farmakas. $\mathrm{N}$ is the number of days according to the above classification.

\begin{tabular}{|c|c|c|c|c|c|c|c|c|c|c|c|c|c|c|c|c|c|c|c|c|}
\hline \multirow{2}{*}{$\begin{array}{l}\text { Cloudy } \\
\text { Month }\end{array}$} & \multicolumn{5}{|c|}{$\mathbf{G}_{\mathrm{d}}$} & \multicolumn{5}{|c|}{$B_{\text {nd }}$} & \multicolumn{5}{|c|}{$B_{d}$} & \multicolumn{5}{|c|}{$D_{d}$} \\
\hline & $\mathrm{N}$ & \begin{tabular}{|l|} 
Mean \\
\end{tabular} & \begin{tabular}{|l|} 
StDev \\
\end{tabular} & \begin{tabular}{|l|} 
Median \\
\end{tabular} & Max & $\mathrm{N}$ & Mean & StDev & Median & Max & $\mathrm{N}$ & Mean & StDev & Median & Max & $\mathrm{N}$ & Mean & StDev & Median & Max \\
\hline 1 & 59 & 4.34 & 1.41 & 4.46 & 6.79 & 59 & 2.18 & 1.87 & 1.58 & 7.36 & 59 & 0.96 & 0.81 & 0.70 & 3.21 & 59 & 3.34 & 0.96 & 3.38 & 5.68 \\
\hline 2 & 34 & 5.69 & 1.89 & 6.12 & 8.69 & 34 & 2.67 & 2.18 & 2.32 & 7.79 & 34 & 1.34 & 1.03 & 1.17 & 3.59 & 34 & 4.34 & 1.43 & 4.48 & 7.11 \\
\hline 3 & 23 & 6.73 & 2.27 & 7.24 & 9.16 & 23 & 2.35 & 1.96 & 2.09 & 6.43 & 23 & 1.35 & 1.06 & 1.18 & 3.27 & 23 & 5.31 & 1.76 & 5.54 & 7.94 \\
\hline 4 & 21 & 10.39 & 1.45 & 10.72 & 12.38 & 21 & 5.60 & 2.38 & 5.68 & 10.76 & 21 & 3.38 & 1.36 & 3.16 & 6.44 & 21 & 6.99 & 1.20 & 6.99 & 9.51 \\
\hline 5 & 10 & 11.69 & 1.97 & 12.52 & 13.92 & 10 & 8.06 & 3.91 & 8.79 & 13.76 & 10 & 4.86 & 2.35 & 5.49 & 7.84 & 10 & 6.78 & 0.87 & 6.79 & 8.46 \\
\hline 6 & 0 & & & & & 0 & & & & & 0 & & & & & 0 & & & & \\
\hline 7 & 1 & 13.73 & $*$ & 13.73 & 13.73 & 1 & 9.69 & $*$ & 9.69 & 9.69 & 1 & 5.67 & $*$ & 5.67 & 5.67 & 1 & 8.01 & * & 8.01 & 8.01 \\
\hline 8 & 0 & & & & & 0 & & & & & 0 & & & & & 0 & & & & \\
\hline 9 & 3 & 10.48 & 0.63 & 10.12 & 11.21 & 3 & 10.02 & 1.96 & 9.12 & 12.27 & 3 & 5.65 & 1.13 & 5.00 & 6.96 & 3 & 4.82 & 0.49 & 5.10 & 5.11 \\
\hline 10 & 11 & 6.54 & 1.66 & 6.71 & 8.64 & 11 & 4.89 & 2.89 & 4.69 & 10.53 & 11 & 2.57 & 1.49 & 2.57 & 5.69 & 11 & 3.93 & 1.05 & 4.24 & 5.33 \\
\hline 11 & 21 & 4.81 & 1.45 & 5.02 & 7.09 & 21 & 2.63 & 2.27 & 2.05 & 8.64 & 21 & 1.22 & 1.02 & 0.94 & 3.90 & 21 & 3.54 & 0.92 & 3.55 & 5.19 \\
\hline 12 & 39 & 3.99 & 1.32 & 4.28 & 5.86 & 39 & 2.48 & 1.91 & 2.23 & 6.43 & 39 & 1.03 & 0.82 & 0.97 & 2.67 & 39 & 2.93 & 0.73 & 3.09 & 4.40 \\
\hline P. Cloudy & \multicolumn{5}{|c|}{$\mathbf{G}_{\mathrm{d}}$} & \multicolumn{5}{|c|}{$B_{n d}$} & \multicolumn{5}{|c|}{$B_{d}$} & \multicolumn{5}{|c|}{$D_{d}$} \\
\hline Month & $\mathrm{N}$ & \begin{tabular}{|l|} 
Mean \\
\end{tabular} & \begin{tabular}{|l|} 
StDev \\
\end{tabular} & \begin{tabular}{|l|} 
Median \\
\end{tabular} & Max & $\mathrm{N}$ & Mean & StDev & Median & Max & $\mathrm{N}$ & Mean & StDev & Median & Max & $\mathrm{N}$ & Mean & StDev & Median & Max \\
\hline 1 & 80 & 9.35 & 1.76 & 9.43 & 12.33 & 75 & 11.47 & 4.49 & 10.73 & 19.92 & 75 & 5.36 & 2.16 & 5.02 & 9.20 & 75 & 3.75 & 0.99 & 3.55 & 6.23 \\
\hline 2 & 74 & 11.53 & 2.27 & 11.61 & 16.36 & 72 & 11.62 & 4.59 & 11.25 & 19.90 & 72 & 6.23 & 2.58 & 6.06 & 11.23 & 72 & 5.13 & 1.04 & 4.99 & 7.43 \\
\hline 3 & 73 & 15.71 & 36 & 16.05 & 2 & 70 & 13.79 & & & 34 & 69 & 47 & 2.86 & 67 & & 69 & .84 & 41 & 66 & 10.87 \\
\hline 4 & 60 & 19.38 & 3.06 & 19.34 & 24.30 & 60 & 15.87 & 3.78 & 15.83 & 23.68 & 60 & 10.62 & 2.80 & 10.40 & 16.53 & 60 & 8.32 & 1.41 & 8.21 & 11.64 \\
\hline 5 & 69 & 20.37 & 3.42 & 20.40 & 26.09 & 69 & 15.82 & 4.33 & 15.90 & 26.06 & 69 & 11.01 & 3.22 & 10.91 & 17.87 & 69 & 9.27 & 1.13 & 9.22 & 11.90 \\
\hline 6 & 69 & 21.16 & 3.13 & 21.39 & 26.66 & 69 & 16.46 & 3.94 & 16.87 & 23.59 & 69 & 11.41 & 2.84 & 11.41 & 16.90 & 69 & 9.71 & 0.97 & 9.74 & 11.81 \\
\hline 7 & 40 & 23.23 & 2.55 & 23.45 & 26.74 & 40 & 19.78 & 3.61 & 20.58 & 24.46 & 40 & 13.95 & 2.70 & 14.33 & 17.83 & 40 & 9.23 & 0.63 & 9.21 & 10.81 \\
\hline 8 & 60 & 20.74 & 2.72 & 21.24 & 25.32 & 60 & 19.40 & 3.70 & 19.74 & 25.58 & 60 & 13.27 & 2.71 & 13.50 & 18.09 & 60 & 7.41 & 0.80 & 7.31 & 9.51 \\
\hline 9 & 66 & 16.74 & 2.62 & 16.75 & 22.10 & 66 & 17.42 & 3.78 & 17.61 & 24.03 & 66 & 11.05 & 2.67 & 11.05 & 16.20 & 66 & 5.65 & 0.56 & 5.57 & 7.47 \\
\hline 10 & 84 & 13.08 & 2.23 & 13.04 & 18.09 & 84 & 14.62 & 3.43 & 14.65 & 21.59 & 84 & 8.21 & 2.20 & 8.05 & 13.23 & 84 & 4.83 & 0.79 & .86 & 6.78 \\
\hline 11 & 94 & 10.15 & 1.74 & 10.02 & 13.44 & 94 & 12.65 & 3.79 & 12.54 & 20.52 & 94 & 6.23 & 1.98 & 5.99 & 10.48 & 94 & 3.85 & 0.70 & 3.82 & 5.71 \\
\hline 12 & 94 & 8.38 & 1.52 & 8.29 & 11.28 & 94 & 11.18 & 4.54 & 11.03 & 19.98 & 94 & 4.94 & 2.04 & 4.80 & 9.10 & 94 & 3.41 & 0.84 & 3.29 & 5.84 \\
\hline Clear & \multicolumn{5}{|c|}{$\mathbf{G}_{\mathrm{d}}$} & \multicolumn{5}{|c|}{$B_{n d}$} & \multicolumn{5}{|c|}{$B_{d}$} & \multicolumn{5}{|c|}{$D_{d}$} \\
\hline Month & $\mathrm{N}$ & Mean & StDev & \begin{tabular}{|l|} 
Median \\
\end{tabular} & Max & $\mathrm{N}$ & Mean & StDev & Median & Max & $\mathrm{N}$ & Mean & StDev & Median & Max & $\mathrm{N}$ & Mean & StDev & Median & Max \\
\hline 1 & 16 & 12.75 & 0.78 & 12.82 & 14.52 & 14 & 20.48 & 3.10 & 20.62 & 23.44 & 14 & 9.57 & 1.55 & 9.76 & 11.56 & 14 & 3.10 & 1.33 & 2.63 & 6.60 \\
\hline 2 & 32 & 16.01 & 1.55 & 16.13 & 18.76 & 23 & 20.85 & 4.66 & 22.44 & 27.08 & 20 & 11.98 & 1.13 & 11.81 & 14.65 & 20 & 3.59 & 0.98 & 3.41 & 6.04 \\
\hline 3 & 59 & 21.03 & 1.81 & 20.67 & 24.94 & 48 & 25.10 & 3.89 & 24.75 & 31.04 & 47 & 15.53 & 2.53 & 15.03 & 20.32 & 47 & 5.33 & 1.03 & .18 & 8.15 \\
\hline 4 & 69 & 26.06 & 1.43 & 26.25 & 28.93 & 51 & 28.38 & 3.29 & 28.88 & 33.26 & 51 & 19.56 & 2.20 & 19.92 & 23.25 & 51 & 6.21 & 0.95 & 6.22 & 8.51 \\
\hline 5 & 76 & 28.73 & 1.35 & 28.95 & 31.90 & 75 & 27.44 & 2.95 & 27.40 & 32.23 & 75 & 20.11 & 2.05 & 20.10 & 23.27 & 75 & 8.59 & 1.09 & 8.46 & 12.06 \\
\hline 6 & 81 & 29.81 & 1.13 & 30.04 & 31.75 & 81 & 27.93 & 2.31 & 28.17 & 32.16 & 81 & 20.60 & 1.72 & 20.95 & 23.54 & 81 & 9.17 & 0.72 & 9.13 & 11.21 \\
\hline 7 & 114 & 29.26 & 1.12 & 29.32 & 31.40 & 114 & 28.67 & 1.91 & 29.20 & 31.36 & 114 & 21.03 & 1.45 & 21.48 & 23.25 & 114 & 8.20 & 0.75 & 8.21 & 11.44 \\
\hline 8 & 95 & 26.48 & 1.52 & 26.41 & 29.09 & 95 & 28.55 & 2.16 & 28.97 & 32.04 & 95 & 20.13 & 1.69 & 20.30 & 22.80 & 95 & 6.28 & 0.75 & 6.19 & 8.18 \\
\hline 9 & 81 & 22.59 & 1.52 & 22.68 & 25.26 & 81 & 27.28 & 2.00 & 27.61 & 30.18 & 81 & 17.68 & 1.54 & 17.87 & 20.51 & 81 & 4.88 & 0.60 & 4.95 & 6.09 \\
\hline 10 & 60 & 17.73 & 1.71 & 17.84 & 20.64 & 60 & 24.17 & 1.95 & 24.30 & 28.23 & 60 & 13.70 & 1.47 & 13.73 & 17.01 & 60 & 3.99 & 0.74 & 3.89 & 5.64 \\
\hline 11 & 35 & 13.28 & 1.01 & 13.08 & 15.50 & 35 & 21.31 & 1.98 & 21.40 & 25.41 & 35 & 10.43 & 1.20 & 10.19 & 13.02 & 35 & 2.80 & 0.53 & 2.59 & 4.13 \\
\hline 12 & 22 & 11.32 & 0.28 & 11.28 & 11.79 & 22 & 20.60 & 1.17 & 20.96 & 22.19 & 22 & 9.01 & 0.54 & 9.14 & 9.74 & 22 & 2.27 & 0.40 & 2.11 & 3.34 \\
\hline
\end{tabular}


The results of the partition of the daily global, normal incidence, horizontal beam radiation and diffuse radiation values on the basis of the corresponding $\mathrm{K}_{\mathrm{T}}$ values (i.e., the criteria for classifying day type) are reported in Table 5. The discrepancy between the number of days in the corresponding individual radiation component is a result of the different missing days in each of them. The monthly average frequency of days according to their type gives an initial indication of the relative viability of different solar collector types. For example, concentrating solar collectors operate best under clear day conditions and, to a much lesser extent, under partially cloudy days. The major difference between day types is the significant reduction in the beam radiation which also affects the global irradiation level. For the current station, the monthly average daily beam normal radiation available for energy conversion on partially cloudy days is reduced by a factor ranging from 0.54 to 0.69 relative to that available on clear days. Regarding the global radiation, the reduction factor for partially cloudy days to that on clear days ranged from 0.71 to 0.79 . Almost similar figures were obtained by Kudish and Ianetz (1996) at Beer Sheva in Israel.

The descriptive statistics of the sunshine duration as well as the relative sunshine duration are presented in Table 6 for each month of the year. The annual daily average is 7.0 hours with an annual total of 2555 hours. The monthly mean daily values range between 3.4 hours in January to 10.3 hours in July. The maximum daily value is 11.7 hours and it occurs in the summer months. The site is exposed to an average of about $57 \%$ of daily sunshine over the year. The monthly mean daily relative sunshine duration $(\sigma)$ ranges between 0.35 in January to 0.73 in July.

Table (6). Descriptive statistics of mean daily sunshine duration $\left(\mathrm{S}_{\mathrm{d}}\right)(\mathrm{hrs})$ and its mean daily relative sunshine duration $(\sigma)$ for each month of the year.

\begin{tabular}{|c|c|c|c|c|c|c|c|c|c|c|c|c|c|c|c|c|}
\hline \multicolumn{9}{|c|}{ Daily Sunshine Duration $\left(S_{d}\right)$} & \multicolumn{8}{|c|}{ Relative Sunshine Duration $(\sigma)\left(\mathrm{S}_{\mathrm{d}} / \mathrm{S}_{0 \mathrm{~d}}\right)$} \\
\hline Month & $\mathrm{N}$ & Mean & StDev & CV(\%) & Q1 & Median & Q3 & Max & $\mathrm{N}$ & Mean & StDev & $\mathrm{CV}(\%)$ & Q1 & Median & Q3 & Max \\
\hline 1 & 155 & 3.4 & 2.30 & 66.8 & 1.4 & 3.6 & 5.6 & 7.1 & 155 & 0.345 & 0.230 & 66.8 & 0.138 & 0.364 & 0.552 & 0.706 \\
\hline 2 & 140 & 4.6 & 2.47 & 54.1 & 2.7 & 4.8 & 6.9 & 8.3 & 140 & 0.425 & 0.229 & 53.9 & 0.258 & 0.446 & 0.644 & 0.754 \\
\hline 3 & 155 & 6.4 & 2.77 & 43.1 & 4.9 & 7.0 & 8.8 & 9.8 & 155 & 0.546 & 0.235 & 43.0 & 0.411 & 0.597 & 0.761 & 0.799 \\
\hline 4 & 150 & 7.9 & 2.75 & 34.6 & 6.1 & 9.2 & 10.2 & 10.7 & 150 & 0.615 & 0.211 & 34.3 & 0.475 & 0.709 & 0.793 & 0.809 \\
\hline 5 & 155 & 8.8 & 2.55 & 29.0 & 6.8 & 9.9 & 11.0 & 11.5 & 155 & 0.635 & 0.183 & 28.8 & 0.483 & 0.721 & 0.793 & 0.811 \\
\hline 6 & 150 & 9.5 & 2.15 & 22.6 & 7.9 & 10.4 & 11.4 & 11.7 & 150 & 0.665 & 0.150 & 22.6 & 0.551 & 0.723 & 0.796 & 0.817 \\
\hline 7 & 155 & 10.3 & 1.44 & 14.0 & 10.1 & 11.0 & 11.2 & 11.6 & 155 & 0.732 & 0.102 & 13.9 & 0.709 & 0.782 & 0.799 & 0.813 \\
\hline 8 & 155 & 9.4 & 1.56 & 16.7 & 8.4 & 10.0 & 10.6 & 11.0 & 155 & 0.706 & 0.117 & 16.6 & 0.638 & 0.760 & 0.797 & 0.809 \\
\hline 9 & 150 & 8.1 & 1.84 & 22.8 & 6.6 & 8.9 & 9.6 & 10.1 & 150 & 0.664 & 0.150 & 22.5 & 0.547 & 0.742 & 0.789 & 0.800 \\
\hline 10 & 155 & 6.5 & 1.96 & 30.3 & 5.1 & 6.8 & 8.2 & 9.0 & 155 & 0.582 & 0.174 & 29.8 & 0.463 & 0.619 & 0.746 & 0.778 \\
\hline 11 & 150 & 4.9 & 2.07 & 41.9 & 3.8 & 5.1 & 6.9 & 7.8 & 150 & 0.486 & 0.203 & 41.7 & 0.373 & 0.510 & 0.682 & 0.743 \\
\hline 12 & 155 & 3.9 & 2.12 & 54.9 & 2.2 & 3.9 & 5.7 & 6.8 & 155 & 0.398 & 0.218 & 54.9 & 0.228 & 0.402 & 0.590 & 0.705 \\
\hline Year & 1825 & 7.0 & 3.16 & 45.2 & 4.8 & 7.1 & 9.8 & 11.7 & 1825 & 0.567 & 0.224 & 39.5 & 0.425 & 0.633 & 0.769 & 0.817 \\
\hline
\end{tabular}

Furthermore, the daily sunshine duration was compared with the daily global irradiation. As can be seen in Fig. 18a there is a strong relationship between the two variables. Figure $18 \mathrm{~b}$ shows the relationship between the clearness index $\left(\mathrm{K}_{\mathrm{T}}\right)$ and the relative sunshine duration $(\sigma)$. As it can be seen there is a strong relationship between the two variables. Most of the points are spread within the prediction intervals of the regression line. If the residuals of $\mathrm{K}_{\mathrm{T}}$ are greater than 0.2 , then the points are excluded from the analysis (Scharmer and Greif, 2000). The deviations of residuals from the calculated regression line are lower than 0.15 indicating very good quality of the data. The relationship between the daily clearness index $\left(\mathrm{K}_{\mathrm{T}}\right)$ and the relative sunshine duration $(\sigma)$ is also shown in Fig. 18b. Almost similar values for the intercept and slope were found for other two locations in Cyprus (Kalogirou et al. 2017). 


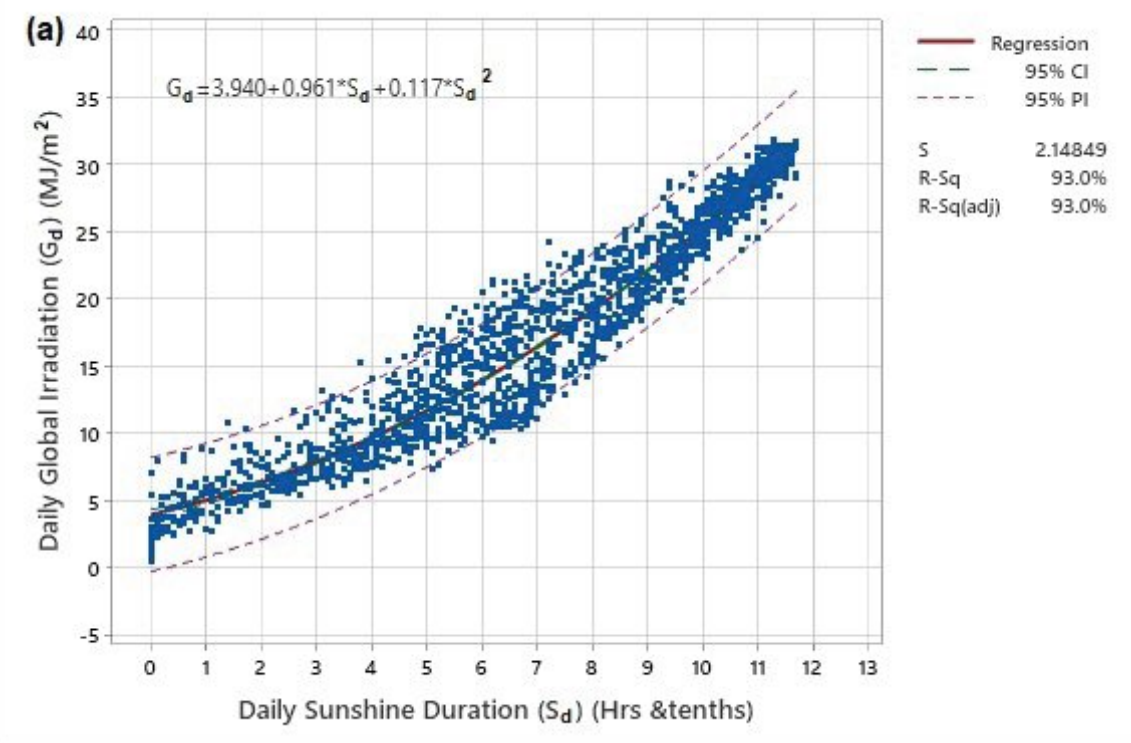

Figure (18a). Relationship between the daily global radiation $\left(G_{d}\right)$ in $M J / m^{2}$ and daily sunshine duration $\left(\mathrm{S}_{\mathrm{d}}\right)$.

(b)

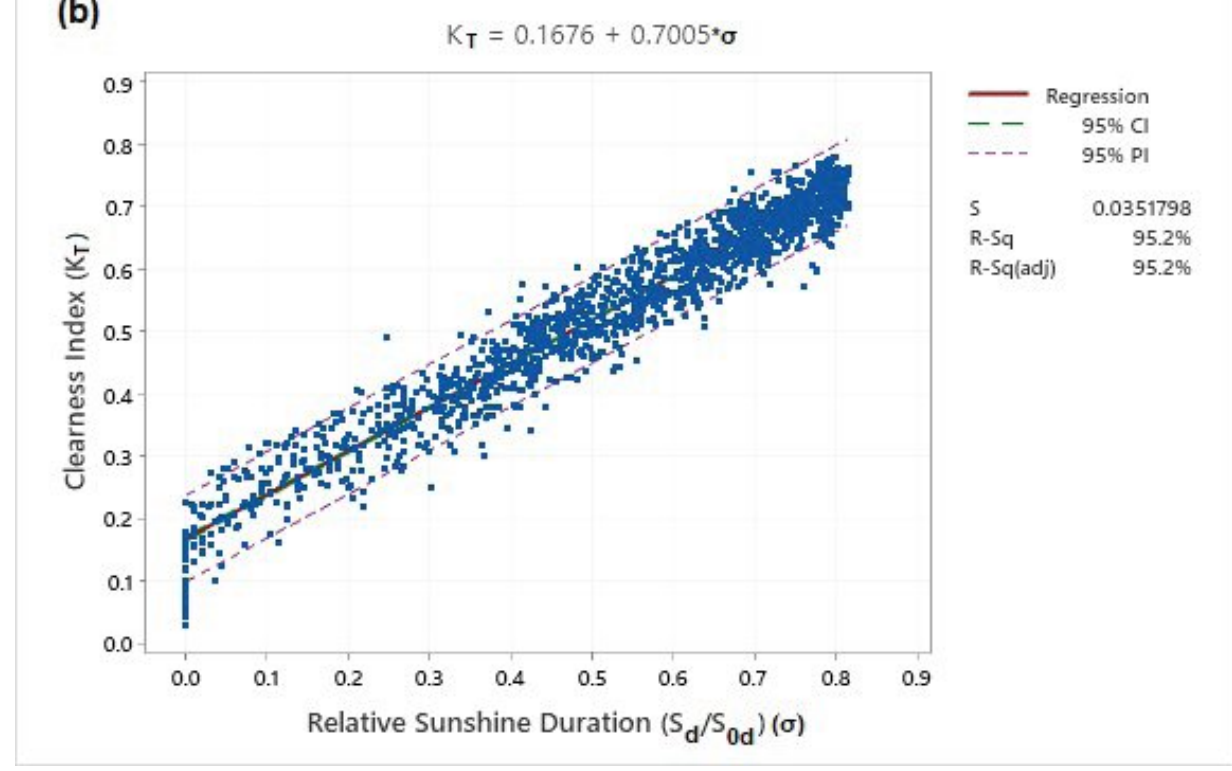

Figure (18b). Distribution of clearness index $\left(\mathrm{K}_{\mathrm{T}}\right)$ against relative sunshine duration $(\sigma)$ at Farmakas.

\subsubsection{Daily Diffuse fraction $\left(K_{D}\right)$}

The daily diffuse fraction $\left(\mathrm{K}_{\mathrm{D}}\right)$ is the ratio of daily diffuse radiation to the daily global radiation. Table 7 presents the descriptive statistics of this fraction. $K_{D}$ ranges from 0.28 in summer to 0.55 in winter. Fig. 19a shows the relationship between the daily diffuse fraction and the daily clearness index $\left(\mathrm{K}_{\mathrm{T}}\right)$, while Fig. 19b shows the relationship between the daily diffuse fraction and the relative sunshine duration. Both equations 
can be used to estimate daily diffuse radiation. The quadratic equations associated with the said relationships for the period 2016-2019 have the following forms:

$$
\begin{array}{ll}
\mathrm{K}_{\mathrm{D}}=1.145-1.81 \mathrm{~K}_{\mathrm{T}}+0.783 \mathrm{~K}_{\mathrm{T}}^{2} & \mathrm{R}^{2}=0.83 \\
\mathrm{~K}_{\mathrm{D}}=0.927+1.403 \sigma+0.706 \sigma^{2} & \mathrm{R}^{2}=0.85
\end{array}
$$

The linear regressions between the said relationships show slightly lower correlation coefficients. Almost similar equations were obtained by Kalogirou et al. (2017) for Athalassa and Larnaca.

\begin{tabular}{|c|c|c|c|c|c|c|c|c|c|c|c|c|c|c|c|c|c|c|}
\hline & \multicolumn{9}{|c|}{ Diffuse fraction $\left(K_{D}\right)$} & \multicolumn{9}{|c|}{ Beam Horizontal Ratio $\left(\mathrm{K}_{\mathrm{B}}\right)$} \\
\hline lonth & $\mathrm{N}$ & ean & StDev & CV (\%) & Min & Q1 & Median & Q3 & Max & $\mathrm{N}$ & Mean & StDev & CV (\%) & Min & Q1 & Median & Q3 & Max \\
\hline 1 & 148 & 55 & 43 & 72 & 165 & 41 & 33 & 780 & 0.960 & 148 & 33 & 45 & 56.61 & .025 & 209 & 132 & .652 & .830 \\
\hline 2 & 126 & 516 & 226 & 43.89 & 169 & 336 & 468 & 0.673 & 0.947 & 126 & 479 & 0.227 & 11 & 0.053 & 291 & 521 & 664 & .836 \\
\hline 3 & 139 & 42 & 99 & & & & & & 7 & 139 & & & & 23 & & & & \\
\hline 4 & 132 & 399 & 0.171 & 42.82 & 173 & 0.253 & 0.378 & 0.513 & 0.940 & 132 & 0.588 & 0.173 & 44 & 0.056 & 0.456 & 604 & .743 & 0.827 \\
\hline 5 & 154 & 95 & 24 & 3 & 3 & 01 & & & & 154 & & 24 & & 89 & & & & 776 \\
\hline 6 & 150 & 381 & 0.094 & 24.57 & 0.257 & 0.300 & 0.363 & 0.454 & 0.714 & 150 & 0.617 & 0.094 & 15.29 & 0.280 & 0.545 & 34 & 0.700 & 0.742 \\
\hline 7 & 155 & 314 & 070 & 22.25 & 226 & 264 & 94 & 348 & 0.583 & 155 & 684 & .070 & 29 & 413 & 651 & 06 & .736 & .773 \\
\hline 8 & 155 & 0.287 & 0.075 & 26.32 & 185 & 219 & & 0.337 & 0.496 & 155 & 11 & 0.076 & & 0.500 & 0.659 & & 0.778 & 0.814 \\
\hline 9 & 150 & 0.279 & .085 & 30.54 & 167 & 210 & 55 & 334 & 0.519 & 150 & 0.720 & 0.085 & 11.87 & 0.478 & 0.665 & 42 & 0.789 & .833 \\
\hline 10 & 155 & 0.336 & 0.132 & 39.25 & 154 & 0.233 & & 0.391 & 0.876 & 155 & 0.661 & 0.134 & 20.24 & 0.125 & 0.609 & & .765 & 0.841 \\
\hline 11 & 150 & 0.403 & 0.198 & 49.10 & 0.158 & 0.254 & 0.356 & 0.478 & 0.965 & 150 & 0.590 & 0.199 & 33.74 & 0.033 & 0.514 & 39 & 0.740 & .840 \\
\hline 12 & 155 & 0.482 & 0.229 & 47.41 & 0.162 & 0.286 & 0.458 & 0.658 & 0.972 & 155 & 0.514 & 0.230 & 44.77 & 0.023 & 0.337 & 36 & 0.710 & 0.834 \\
\hline Year & 1769 & 0.396 & 0.185 & 46.61 & 0.154 & 0.261 & 0.346 & 0.474 & 0.977 & 1769 & 0.598 & 0.188 & 31.40 & 0.023 & \begin{tabular}{|l|}
0.518 \\
\end{tabular} & 0.650 & \begin{tabular}{|l|}
0.737 \\
\end{tabular} & 0.841 \\
\hline
\end{tabular}

Table (7). Descriptive statistics of the daily diffuse fraction $\left(K_{D}\right)$ and beam horizontal fraction $\left(K_{B}\right)$

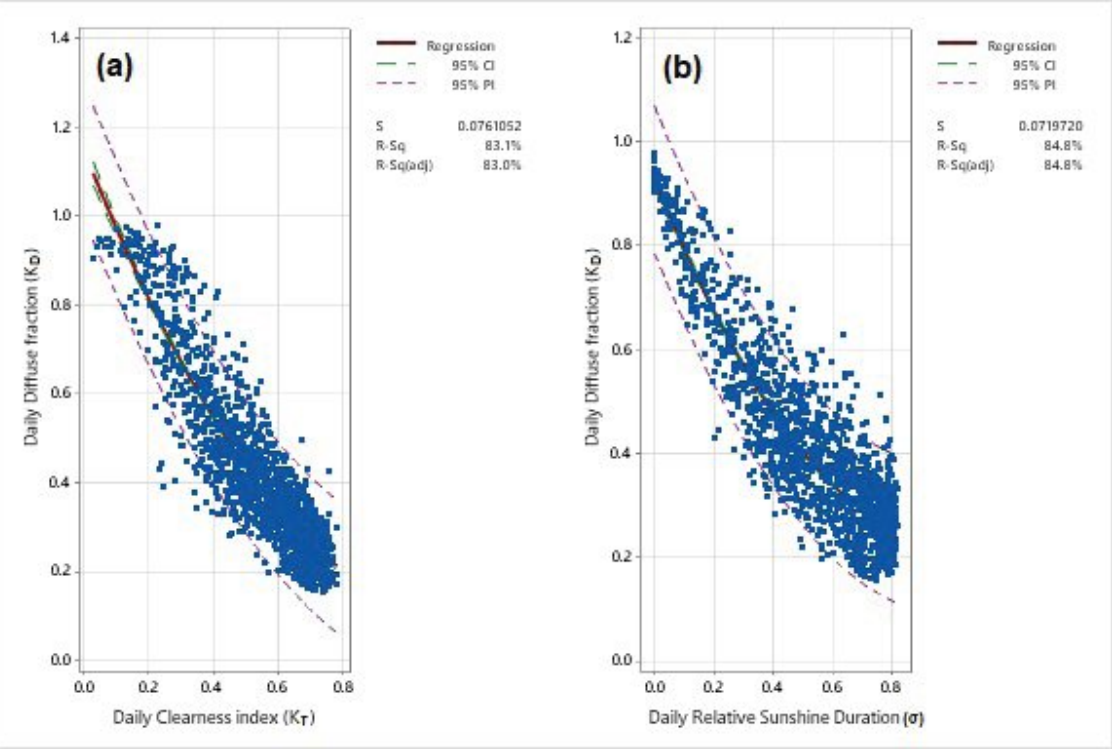

Figure (19. a) Relationship between the daily diffuse fraction (KD) and the daily clearness index (KT), b) Relationship between the daily diffuse fraction (KD) and the relative sunshine ( $\sigma$ ).

\subsubsection{Daily horizontal Beam ratio $\left(K_{B}\right)$}

The daily horizontal beam fraction $\left(\mathrm{K}_{\mathrm{B}}\right)$ is defined as the ratio of daily horizontal beam irradiation $\left(\mathrm{B}_{\mathrm{d}}\right)$ to the daily global irradiation $\left(G_{d}\right)$. The daily horizontal beam clearness index is defined as the ratio of daily horizontal irradiation $\left(B_{d}\right)$ to the external horizontal irradiation $\left(G_{0 d}\right) . K_{B}$ is less variable during the summer months, but it shows high variability during the rest of the year (Table 7). Similar variability occurs for the 
beam clearness index. The quadratic equations associated with the clearness index and the relative sunshine duration have the following forms:

$$
\begin{aligned}
& K_{B}=-0.153+1.805 K_{T}-0.769 K_{T}^{2} \quad R^{2}=0.85 \\
& K_{B}=0.066-1.404 \sigma+0.701 \sigma^{2} \quad R^{2}=0.84 \ldots \ldots
\end{aligned}
$$

\subsubsection{Modeling daily diffuse radiation}

Various empirical relationships can be used to estimate the daily diffuse radiation. For this purpose, the daily diffuse fraction $K_{D}=D_{d} / G_{d}$ is correlated to the first, second and third order correlations with the clearness index $K_{T}=G_{d} / G_{0 d}$ and the relative sunshine duration $\sigma=S_{d} / S_{0 d}$. It is found that the third order correlations do not improve the accuracy of the estimation of diffuse irradiation. The models was developed based on a four years 'training data set' (2016-2019) and the performance of the models were tested against the 'validation data set' of the year 2020, using the most popular statistical methods such as Mean Bias Error (MBE), Root Mean Square Error (RMSE), and the coefficient of determination $\left(\mathrm{R}^{2}\right)$. For higher modeling accuracy, these estimators should be closer to zero, and $\mathrm{R}^{2}$ should approach 1 . Table 8 summarizes the results of estimated diffuse irradiation based on the validation data set (year 2020) based on statistical estimators as described above. Both equations show almost similar errors.

Table (8). Mean Bias Error (MBE), Root Mean Square Error (RMSE) and coefficient of determination ( $\left.\mathrm{R}^{2}\right)$ for the estimated diffuse irradiation based on Eq. (36 and 37) and the calculated diffuse irradiation $\left(\mathrm{G}_{\mathrm{d}}-\mathrm{B}_{\mathrm{d}}\right)$ in $\mathrm{MJ} / \mathrm{m}^{2}$.

\begin{tabular}{|c|c|c|c|}
\hline Estimated Daily Diffuse & MBE $\left(\mathrm{MJ} / \mathrm{m}^{2}\right)$ & $\mathrm{RMSE}\left(\mathrm{MJ} / \mathrm{m}^{2}\right)$ & $\mathrm{R}^{2}$ \\
\hline Eq. (36) & 0.139 & 1.015 & 0.84 \\
\hline Eq. (37) & 0.070 & 1.013 & 0.84 \\
\hline
\end{tabular}

\section{CONCLUSIONS}

Hourly data of global horizontal irradiance $(\mathrm{G})$ were obtained from the automatic weather station of Farmakas, an inland location in Cyprus at the height of $833 \mathrm{~m}$, covering the period 2016-2020. A CM-11 Kipp \& Zonen pyranometer was used for the measurement of global radiation. For the sunshine duration measurements, a Kipp \& Zonen CSD3 sunshine duration sensor is used. The sensor, at the same time, measures the direct normal irradiance $\left(\mathrm{B}_{\mathrm{n}}\right)$ in $\mathrm{W} / \mathrm{m}^{2}$. The first objective of the study was the assessment of the measured radiation components. For this purpose, the data underwent an extensive quality control process for both hourly and daily values which was followed by a statistical analysis of the shortwave radiation components and the derived indices. The second objective of the study refers to the modeling of the diffuse fraction and the estimation of diffuse and direct normal irradiance based on the BRL model.

Monthly mean hourly values of shortwave irradiances are shown by means of isoline diagrams. These values are considered representative of the solar radiation behavior along a typical year and can be useful for exploiting solar energy applications. July was found to be the month with maximum values of direct horizontal and global radiation. At noon, in July, about $675 \mathrm{~W} / \mathrm{m}^{2}$ and $940 \mathrm{~W} / \mathrm{m}^{2}$ are reported, respectively. The estimated diffuse irradiance fluctuates between $160 \mathrm{~W} / \mathrm{m}^{2}$ and $330 \mathrm{~W} / \mathrm{m}^{2}$. Seasonal analysis allows highlighting the difference between summer and winter irradiation conditions.

Monthly means of clearness index $\left(\mathrm{k}_{\mathrm{t}}\right)$ range between 0.3 and 0.6 with the highest occurring in summer. Values higher than 0.65 are obtained for the period of May-September, indicating a high percentage of clear days. Almost similar pattern is followed by the beam fraction $\left(\mathrm{k}_{\mathrm{b}}\right)$. On the other hand, the diffuse fraction $\left(\mathrm{k}_{\mathrm{d}}\right)$ shows higher values in winter and the lowest in summer ranging from 0.3 to 0.7 . However, $\mathrm{k}_{\mathrm{d}}$ has a lot of 
outliers in the summer months, since few days with clouds can cause this variability.

The BRL model (a multiple variable logistic model for the diffuse solar fraction) was used to obtain hourly diffuse radiation and from that the direct normal solar radiation. Considering the error analysis, the results show that the BRL model can estimate satisfactorily both the diffuse solar irradiance as well as the direct normal irradiance. The model was developed based on a four years 'training data set' (2016-2019) and the performance of the model was tested against the 'validation data set' of the year 2020, using the most popular statistical methods such as Mean Bias Error (MBE), Root Mean Square Error (RMSE), and the coefficient of determination $\left(\mathrm{R}^{2}\right)$. The estimated parameters were close to those obtained by Ridley et al. (2010) at Adelaide of Australia, i.e., a location with similar climatic conditions to Cyprus.

The annual average daily global radiation intensity is around $17.5 \mathrm{MJ} / \mathrm{m}^{2}$, whereas that for horizontal beam and diffuse radiation is $11.4 \mathrm{MJ} / \mathrm{m}^{2}$ and $5.9 \mathrm{MJ} / \mathrm{m}^{2}$, respectively. Consequently, the fraction of the beam component of the global radiation is relatively high, i.e., the annual average daily fraction is $\geq 0.600$ at this site. The monthly mean daily values for the global radiation range between 7.5 and $27.5 \mathrm{MJ} / \mathrm{m}^{2}$, for the direct horizontal radiation they range between 4.0 and $19.0 \mathrm{MJ} / \mathrm{m}^{2}$ and for the diffuse radiation they fluctuate between 3.0 and $9.5 \mathrm{MJ} / \mathrm{m}^{2}$. Almost, similar values were obtained in Israel (Kudish and Ianetz, 1996).

The annual average of daily clearness index $\left(\mathrm{K}_{\mathrm{T}}\right)$ is 0.565 with a standard deviation of 0.161 . The data were divided according to the clearness index value in three sky conditions: clear, partly cloudy and cloudy. The annual number of cloudy days is $44.4(12.16 \%)$, the respective number for partially cloudy days is 172.6 (47.29\%) and 148 days are classified as clear days representing $40.55 \%$ of the annual number of days. The annual daily average sunshine duration is 7.0 hours with an annual total of 2555 hours. The monthly mean daily values range between 3.4 hours in January to 10.3 hours in July. The maximum daily value is 11.7 hours and it occurs in the summer months. The monthly mean daily relative sunshine duration ranges between 0.35 in January to 0.73 in July.

This work has specifically contributed to the characterization and analysis of hourly and daily solar radiation. As shown it is proved that this is a valid method to decompose global solar radiation to its direct and diffuse components by using hourly measurements of global radiation and sunshine duration, which is valuable for engineers.

\section{ACKNOWLEDGMENTS}

The authors would like to thank the Meteorological Department of Cyprus for providing the solar radiation data used in this study.

\section{NOMENCLATURE}
AST
Apparent Solar Time (hour)
$B$
Hourly horizontal beam irradiance $\left(\mathrm{W} / \mathrm{m}^{2}\right)$
$B_{d}$
Daily horizontal beam irradiation $\left(\mathrm{MJ} / \mathrm{m}^{2}\right)$
$B_{c}$
Hourly horizontal beam irradiance for clear-sky conditions $\left(\mathrm{W} / \mathrm{m}^{2}\right)$
$B_{c d}$
Daily horizontal beam irradiation for clear-sky conditions $\left(\mathrm{MJ} / \mathrm{m}^{2}\right)$
$B_{n}$
Hourly normal beam irradiance $\left(\mathrm{W} / \mathrm{m}^{2}\right)$
$B_{n d}$
Daily normal beam irradiation $\left(\mathrm{MJ} / \mathrm{m}^{2}\right)$
$B_{n c}$
Hourly normal beam irradiance for clear-sky conditions $\left(\mathrm{W} / \mathrm{m}^{2}\right)$
$B_{n c d}$
Daily normal beam irradiation for clear-sky conditions $\left(\mathrm{MJ} / \mathrm{m}^{2}\right)$ 


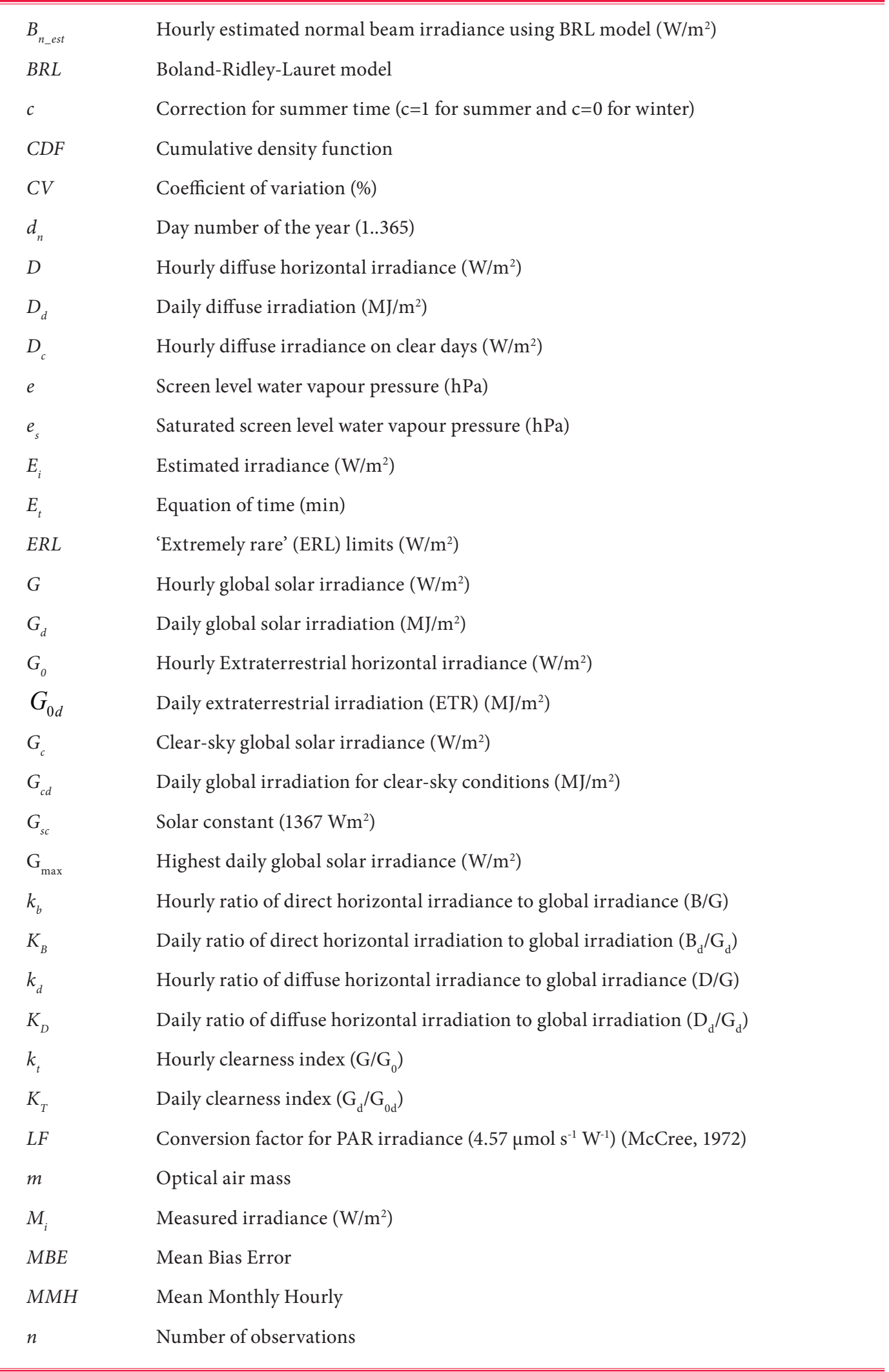


$\mathrm{N}$

PARE

$P A R E_{d}$

$P A R E_{S C}$

$P A R E_{0}$

$P A R E_{0 d}$

PPFD

$P P L$

$P / P_{0}$

$R^{2}$

$R H$

RMSE

$S$

$S_{d}$

$S_{0 d}$

StDev

$t$

$\mathrm{T}_{a}\left({ }^{\circ} \mathrm{C}\right)$

$T_{L K}$

$z$

\section{Greek:}

$\alpha_{s}$

$\delta$

$\delta_{r(m)}$

$\varepsilon$

$\theta_{z}$

$\lambda$

$\lambda_{S T}$

$\sigma$

$\varphi$

$\psi$

$\omega$

$\omega_{s}$
Number of days

Hourly Photosynthetic Active Irradiance $\left(\mathrm{W} / \mathrm{m}^{2}\right)$

Daily Photosynthetic Active Irradiation $\left(\mathrm{MJ} / \mathrm{m}^{2}\right)$

PAR Solar constant $\left(534.6 \mathrm{~W} / \mathrm{m}^{2}\right)$

Hourly Photosynthetic Active Irradiance at the top of the atmosphere $\left(\mathrm{W} / \mathrm{m}^{2}\right)$

Daily Photosynthetic Active Irradiation at the top of the atmosphere $\left(\mathrm{MJ} / \mathrm{m}^{2}\right)$

Hourly Photosynthetic Photon Flux Density $\left(\mu \mathrm{mol} \mathrm{s}^{-1} \mathrm{~m}^{-2}\right)$

'Physically possible' limits $\left(\mathrm{W} / \mathrm{m}^{2}\right)$

Pressure correction for station height

Coefficient of determination

Relative humidity (\%)

Root Mean Square Error

Standard deviation of residuals

Daily sunshine duration (hours)

Astronomical day length (hours)

Standard deviation (Std)

Local time (hour)

Air temperature at screen level $\left({ }^{\circ} \mathrm{C}\right), \mathrm{T}_{\mathrm{a}}(\mathrm{K})=273.16+\mathrm{T}_{\mathrm{a}}\left({ }^{\circ} \mathrm{C}\right)$

Linke Turbidity Factor

Station's elevation (m)

Solar altitude angle (degrees)

Solar declination angle (degrees)

Rayleigh optical depth at air mass $\mathrm{m}$

Correction factor to mean solar distance

Solar zenith angle (SZA) (degrees)

Longitude of the station in degrees (East positive)

Reference longitude of the time zone in degrees (for Cyprus $=30^{\circ}$ )

Relative sunshine duration $\left(\mathrm{S}_{\mathrm{d}} / \mathrm{S}_{0 \mathrm{~d}}\right)$

Latitude of the station in degrees

Persistence parameter in BRL model as an average of lag and lead of clearness index

Hour angle (degrees)

Sunset hour angle (degrees) 


\section{REFERENCES}

Badescu V., 2008. Modeling Solar Radiation at the Earth’s Surface. Recent Advances. Springer Verlag.

Bird R.E., Hulstrom R.L., 1981a. Reviews, evaluation and improvements of direct irradiance models. Trans. ASME J. Solar Energy 103, 182-192.

Bird R.E., Hulstrom R.L., 1981b. A simplified clear sky model for direct and diffuse insolation on horizontal surfaces. Technical Report SERI/TR-642-761. Solar Research Institute, Golden, Colorado.

Bolland J., Ridley B., Brown B., 2008. Models of diffuse solar radiation. Renewable Energy 33,4, 575-584.

Erbs DG., Klein SA. Duffie JA., 1982. Estimation of the diffuse radiation fraction for hourly, daily and monthly average global radiation. Solar Energy 4, 293-302.

Estevez J., Gavilan P., Giraldez J.V., 2011. Guidelines on validation procedures for meteorological data from automatic weather stations. J. Hydrol. 402, 144-154.

Gueymard C., 2004. The sun's total and spectral irradiance for solar energy applications and solar radiation models. Solar Energy 78, 423-453.

Gueymard C.A., 2008. REST2: High performance solar radiation model for cloudless sky irradiance, illuminance, and photosynthetically active radiation- Validation with a benchmark dataset. Solar Energy 82, 3, 272-285.

Gueymard C.A., 2010. Progress in direct irradiance modeling and validation. Procc. ASES Annual Conf. Phoenix, AZ, USA, 2010-ases.org.

Haurwitz B. 1945. Insolation in relation to cloudiness and cloud density. J. Meteorology 2, 154-166.

Hottel HC., 1976. A simple model for estimating the transmittance of direct solar radiation through clear atmospheres. Sol. Energy 18, 129-134.

Ianetz A., Lyubansky V., Setter I., Kriheli B., Evseev E., Kudish A.I., 2007. Inter-comparison of different models for estimating clear sky solar global radiation for the Negev region of Israel. Energy Conversion and Management 48, $259-268$.

Ineichen P., 2008. A broadband simplified version of the Solis clear sky model. Solar Energy 82,8, 758-762.

Iqbal M., 1983. An Introduction to Solar Radiation. Academic Press, Toronto.

Kalogirou S.A., Pashiardis S., Pashiardi A., 2017. Statistical analysis and inter-comparison of the global solar radiation at two sites in Cyprus. Renewable Energy 101, 1102-1123.

Kudish A.I., Ianetz A., 1996. Analysis of daily clearness index, global, and beam radiation for Beer Sheva, Israel: Partition according to day type and statistical analysis. Energy Convers. Mgmt. Vol. 37, No. 4, 405-416.

Long C.N., Shi Y., 2008. An automated quality assessment and control algorithm for surface radiation measurements. Open Atmos. Sci. J. 2, 23-37.

Lui BYH, Jordan RC., 1960. The interrelationship and characteristic distribution of direct, diffuse and total solar radiation. Sol. Energy 4, 1-19.

Maxwell e.l., 1998. METSTAT-The solar radiation model used in the production of the National Solar Radiation Data Base (NSRDB). Solar Energy 62, 4, 263-279.

McCree K.J., 1972. Test of current definitions of photosynthetically active radiation against leaf photosynthesis data. Agric. For. Meteorology 10, 443-453.

Myers D.R., 2013. Solar radiation . Practical Modeling for Renewable Energy Applications. CRC Press.

Orgill JF., Hollands KGT., 1977. Correlation equation for hourly diffuse radiation on a horizontal surface. Solar Energy 19, 357-359. 
Pashiardis S., Kalogirou S.A., Pelengaris A., 2017. Statistical analysis for the characterization of solar energy utilization and inter-comparison of solar radiation at two sites in Cyprus. Applied Energy 190, 1138-1158.

Ridley B., Boland J., Lauret P., 2010. Modelling of diffuse solar fraction with multiple predictors. Renewable Energy 35 , 478-483.

Scharmer K., Greif J., 2000. The European Solar Radiation Atlas. Vol. 1: Fundamentals and maps. Vol. 2: Database and exploitation software. Ecole des Mines de Paris.

Skartveit A., Olseth JH., Tuft ME., 1998. An hourly diffuse fraction model with correction for variability and surface albedo. Solar Energy 63, 3, 173-183.

Younes S., Claywell R., Muneer T., 2005. Quality control of solar radiation data: Present status and proposed new approaches. Energy 30, 1533-1549. 